\title{
Corticosteroids in COVID-19: Is it Rational? A Systematic Review and Meta-Analysis
}

\author{
Pravash Budhathoki $^{1}$ (D) Dhan Bahadur Shrestha ${ }^{2}$ (D) Era Rawal $^{3}$ (D) Sitaram Khadka $^{4}$ (D)
}

Accepted: 9 September 2020 / Published online: 19 October 2020

(C) Springer Nature Switzerland AG 2020

\begin{abstract}
Due to a lack of definitive treatment, many drugs were repurposed for Coronavirus disease (COVID-19) treatment; among them, corticosteroid is one. However, its benefit or harm while treating COVID-19 is not fully studied. Thus, we conducted this meta-analysis to assess the rationality on the use of corticosteroids in COVID-19. Pubmed, Medline, Clinicaltrials.gov, Cochrane library, and Preprint publisher were searched. In the qualitative syntheses, 41, and quantitative studies, 40, were included using PRISMA guidelines. Assessment of heterogeneity was done using the $I$-squared $\left(I^{2}\right)$ test and random/fixed effect analysis was done to determine the odds/risk ratio. We found severely ill COVID-19 patients almost 5 (OR 4.78, 2.76-8.26) times higher odds of getting corticosteroids during their treatment. Similarly, the odds for corticosteroids in addition to standard of care (SOC) were approximately 4 (OR 4.09 , 1. 89-8.84) times higher among intensive care unit (ICU) patients than non-ICU ones. A higher mortality risk with the corticosteroidreceiving group compared with the SOC alone (RR 2.01, 1.12-3.63) was observed. Neither increased discharge rate (RR 0.79, $0.63-0$. 99) nor recovery/improvement rate was shown among the corticosteroid-receiving group (OR 0.24, 0.13-0.43). Approximately, the overall 4-day longer hospital stay was found among the treatment groups (MD 4.19, 2.57-5.81). For the negative conversion of reverse transcription-polymerase chain reaction (RT-PCR), approximately a 3-day (MD 2.42, 1.31-3.53) delay was observed with corticosteroid treatment cases. Our study concludes that more severe and critically ill patients tend to get corticosteroids, and the mortality risk increases with the use of corticosteroids. With the use of corticosteroids, delayed recovery and a longer hospital stay were observed.
\end{abstract}

Keywords COVID-19 $\cdot$ Critical illness $\cdot$ Length of stay $\cdot$ Patient discharge $\cdot$ Survival rate

\section{Background}

An unprecedented outbreak of pneumonia of unknown etiology in Wuhan City, Hubei province in China emerged in December 2019. A novel coronavirus was identified as the

This article is part of the Topical Collection on COVID-19

Electronic supplementary material The online version of this article (https://doi.org/10.1007/s42399-020-00515-6) contains supplementary material, which is available to authorized users.

Sitaram Khadka

sitaram.khadka@naihs.edu.np

1 Dr Iwamura Memorial Hospital, Bhaktapur 44800, Nepal

2 Department of Emergency Medicine, Mangalbare Hospital, Morang, Ulrabari 56600, Nepal

3 Department of Emergency Medicine, Kathmandu Medical College, Kathmandu 44600, Nepal

4 Department of Pharmacy, Shree Birendra Hospital, Nepalese Army Institute of Health Sciences, Kathmandu 44600, Nepal causative agent and was subsequently termed Coronavirus disease (COVID-19) by the World Health Organization (WHO) and declared a pandemic in March 2020. The pandemic has spread all over the globe and created a public health catastrophe also dragging countries into economic crisis. The symptoms of infection range from sore throat, cough, fever to pneumonia, and acute respiratory distress syndrome (ARDS). As of June 2020, over 7 million cases have been confirmed, and more than 400,000 deaths have been recorded due to COVID-19 [1]. Lack of standardized care treatment makes the situation dreadful, and while several trials are being conducted everywhere, there are no specific answers yet. Among these treatment modalities being researched, corticosteroid is one of the most controversial drugs.

Corticosteroids (glucocorticoids) include steroid hormones that are naturally produced in the adrenal cortex of vertebrates and their synthetic analogs. Corticosteroids do not directly attack the viruses, rather act via anti-inflammatory and immunosuppressive properties to minimize the damage created all over the body. The anti-inflammatory activity of glucocorticoids is 
attributed to the repression of pro-inflammatory genes through signal transduction by their steroid receptors. Glucocorticoids inhibit nuclear transcription factor- $\kappa \mathrm{B}(\mathrm{NF}-\mathrm{\kappa} \mathrm{B})$ signaling and further inhibit the transcription and translation of inflammatory factors [2]. Thus, the anti-inflammatory mechanism is the basis for using it in various medical conditions including bacterial or viral pneumonia [3, 4]. Similarly, corticosteroids have been used in the past during severe acute respiratory syndrome coronavirus (SARS-CoV) and the Middle East respiratory syndrome coronavirus (MERS-CoV) outbreaks; although, the evidence of benefit has not been well established and is full of conflicting conclusions $[5,6]$. The use of corticosteroid in the recent pandemic of COVID-19 is based on the genetic homology with the SARS and MERS coronaviruses. Although they are not identical, the exigency for standardized treatment drives clinicians around the world to use it in adjunct to various treatment forms.

With the rapid surge and lack of standardized treatment, the global health situation looks jeopardized. The use of steroids is varied on the geography and severity of patients, ranging from about 7-60\% [7-11]. Ling et al. [7] showing 7.6\% of the study participants receiving steroids while Lu X et al. [11] showed about $60 \%$ of critically ill COVID-19 patients getting steroids in their treatment. Among corticosteroid recipients, the mixed result was shown by studies published. $\mathrm{Wu} \mathrm{C}$ et al. showed decrease mortality when used in COVID-19 patients with ARDS [9], while many other observational retrospective studies showed increased mortality among corticosteroid receiving groups [12-18]. Furthermore, COVID-19 patients taking steroids did not show the better result in clinical improvement and duration of hospital stay and viral clearance in some, and another study could not conclude towards or against significantly urging the current meta-analysis. Therefore, we conducted our study to analyze what patients are prone to receive steroids and determine the clinical outcome with the use of steroids among COVID-19 patients.

The objective of our study is to find the type of patients who are prone to get corticosteroids, overall change in mortality, overall improvement or deterioration among treatment groups in comparison with control, duration of virological clearance, length of hospital stay, the requirement of intubation, and mechanical ventilation.

\section{Methodology}

We used PRISMA guidelines for a systematic review of the available literature [19]:

\section{Criteria for Considering Studies for this Review}

\section{Types of Studies}

We included studies like observational studies, case series, and randomized controlled trials (RCTs) that focused on mortality, clinical improvement, and adverse events among COVID-19 patients taking steroid.

\section{Types of Participants}

We included patients diagnosed with COVID-19 who received steroids and standard of care in the treatment group and patients receiving standard of care (SOC) alone in the control group.

\section{Types of Interventions}

We included patients receiving steroids along with the SOC in the treatment group and standard of care like antivirals, antibiotics, and respiratory support only in the control group.

\section{Types of Outcome Measures}

We analyzed what group of patients were prone to receive steroids, the mortality, requirement for intubation and mechanical ventilation, clinical improvement/deterioration, and length of hospital stay among the patients in the treatment group compared with control.

\section{Outcomes}

Our outcomes were to find which type of patients are prone to get corticosteroids, the overall change in mortality, overall improvement or deterioration among treatment groups in comparison with control, the duration of virological clearance, length of hospital stay, and the requirement of intubation and mechanical ventilation.

\section{Search Methods for Identification of Studies}

Two reviewers (DBS and $\mathrm{PB}$ ) accessed electronic databases like Pubmed, Medline, Clinicaltrials.gov, Cochrane library, Medxriv, Researchsquare, Google Scholar, and WHO clinical trial registry. Reviewers independently searched and evaluated the quality of the studies from January 1 to June 3, 2020. Studies were filtered using COVIDENCE, and data was extracted for quantitative and qualitative analysis. Another reviewer (SK) solved any potential conflict between the two reviewers concerning study selection. The assessment of risk of bias and cross-checking of all the selected studies were done by another reviewer (ER).

\section{Electronic Searches}

We have documented the detailed search strategy in additional file 1 . 
Table 1 Assessment of bias in the included cohort and observational studies using the NHLBI tool

\begin{tabular}{|c|c|c|c|c|}
\hline SN & Study & Score & Percentage & Quality \\
\hline 1 & Chen Q 2020[21] & $6 / 14$ & $42.8 \%$ & Poor \\
\hline 2 & Chen TL 2020 [22] & $8 / 14$ & $57.1 \%$ & Fair \\
\hline 3 & Chrobozcek 2020 [23] & $10 / 14$ & $71 \%$ & Good \\
\hline 4 & Confalonieri 2020 [24] & $12 / 14$ & $85.7 \%$ & Good \\
\hline 5 & Cruz 2020 [25] & $12 / 14$ & $85.7 \%$ & Good \\
\hline 6 & Feng 2020 [26] & $8 / 14$ & $57.1 \%$ & Fair \\
\hline 7 & Gong 2020 [27] & $9 / 14$ & $64.2 \%$ & Good \\
\hline 8 & Guan 2020 [28] & $7 / 14$ & $50 \%$ & Fair \\
\hline 9 & Hong Y 2020 [29] & $7 / 14$ & $50 \%$ & Fair \\
\hline 10 & Hong KS 2020 [30] & $6 / 14$ & $42.8 \%$ & Poor \\
\hline 11 & Hou 2020 [31] & $8 / 14$ & $57.1 \%$ & Fair \\
\hline 12 & Hu 2020 [32] & $8 / 14$ & $57.1 \%$ & Fair \\
\hline 13 & Huang C 2020 [12] & $7 / 14$ & $50 \%$ & Fair \\
\hline 14 & Huang M 2020 [33] & $8 / 14$ & $57.1 \%$ & Fair \\
\hline 15 & Jiang 2020 [34] & $8 / 14$ & $57.1 \%$ & Fair \\
\hline 16 & Lei 2020 [35] & $8 / 14$ & $57.1 \%$ & Fair \\
\hline 17 & Li 2020 [36] & $8 / 14$ & $57.1 \%$ & Fair \\
\hline 18 & Ling 2020 [7] & $9 / 14$ & $64.2 \%$ & Good \\
\hline 19 & Liu T 2020 [37] & $8 / 14$ & $57.1 \%$ & Fair \\
\hline 20 & Liu Y 2020 [38] & $8 / 14$ & $57.1 \%$ & Fair \\
\hline 21 & Lu Xiaofan 2020 [11] & $11 / 14$ & $78.6 \%$ & Good \\
\hline 22 & Sun L 2020 [39] & $6 / 14$ & $42.8 \%$ & Poor \\
\hline 23 & Wang K 2020 [14] & $9 / 14$ & $64.2 \%$ & Good \\
\hline 24 & Wu C 2020 [9] & $9 / 14$ & $64.2 \%$ & Good \\
\hline 25 & Wu J 2020 [16] & $12 / 14$ & $85.7 \%$ & Good \\
\hline 26 & Xu Yonghao 2020 [40] & $7 / 14$ & $50 \%$ & Fair \\
\hline 27 & Yang L 2020 [41] & $7 / 14$ & $50 \%$ & Fair \\
\hline 28 & Yang X 2020 [42] & $8 / 14$ & $57.1 \%$ & Fair \\
\hline 29 & Yu H 2020 [17] & $10 / 14$ & $71.4 \%$ & Good \\
\hline 30 & Zha L 2020 [43] & $10 / 14$ & $71.4 \%$ & Good \\
\hline 31 & Zhao X 2020 [44] & $7 / 14$ & $50 \%$ & Fair \\
\hline 32 & Zhou F 2020 [18] & $8 / 14$ & $57.1 \%$ & Fair \\
\hline
\end{tabular}

Good if they fulfilled $60-100 \%$ of the tool items, Fair if $50-59 \%$ or Poor if $0-49 \%$.

\section{Data Collection and Analysis}

Data extracted from COVIDENCE for quantitative synthesis was analyzed using REVMAN 5.4 software. $\mathrm{I}^{2}$ was used for the assessment of heterogeneity. Random/fixed effect was used for the pooling of studies appropriately. For the length of hospital stay and negative conversion of RT-PCR, the mean differences (MD) was measured between the treatment and control group.

\section{Selection of Studies}

Due to the paucity of RCTs, we included case reports, case series, and observational cohorts for qualitative analysis. For
Table 2 Assessment of bias in included case series using the NHLBI tool

\begin{tabular}{lllll}
\hline SN & Study & Score & Percentage & Quality \\
\hline 1 & Cao 2020 [45] & $8 / 9$ & $88 \%$ & Good \\
2 & Chen Xu 2020 [46] & $7 / 9$ & $77.7 \%$ & Good \\
3 & Lo 2020 [47] & $6 / 9$ & $66.6 \%$ & Good \\
4 & Wan 2020 [48] & $7 / 9$ & $77.7 \%$ & Good \\
5 & Wang D 2020 [49] & $7 / 9$ & $77.7 \%$ & Good \\
6 & Wang D2 2020 [13] & $7 / 9$ & $77.7 \%$ & Good \\
7 & Wang Z 2020 [15] & $7 / 9$ & $77.7 \%$ & Good \\
8 & Xu Y 2020 [50] & $7 / 9$ & $77.7 \%$ & Good \\
9 & Zhang G 2020 [51] & $5 / 9$ & $55.5 \%$ & Fair \\
\hline
\end{tabular}

Good if they fulfilled $60-100 \%$ of the tool items, Fair if $50-59 \%$ or Poor if 0 $49 \%$.

quantitative synthesis, we selected case series and observational studies being there were no published randomized studies comparing the treatment and control of our interest. The studies selected had patients being treated with steroids in addition to other treatment modalities. We excluded reviews, in vitro studies, editorials, letters to editors, simulation studies, molecular docking studies, commentaries, and viewpoints in our synthesis.

\section{Data Extraction and Management}

The quality of the studies was thoroughly evaluated and outcomes of importance for our studies were selected.

\section{Assessment of Risk of Bias in Included Studies}

The National Heart, Lung, and Blood Institute (NHLBI) tool [20] was used for the assessment of the risk of bias for observational studies and case series illustrated in Tables 1 and 2 (details of bias assessment of every single study are available in additional files 2 and 3 ).

\section{Assessment of Heterogeneity}

We assessed the heterogeneity of our included studies using the $I^{2}$ test. The Cochrane Handbook for Systematic Reviews of Intervention was used for the interpretation like 0 to $40 \%$ (might not be important, 30 to $60 \%$ (moderate heterogeneity), 50 to $90 \%$ (substantial heterogeneity), and 75 to $100 \%$ (considerable heterogeneity). The importance of the observed value of $I^{2}$ depends on (i) the magnitude and direction of effects and (ii) the strength of evidence for heterogeneity (e.g., $P$ value from the chi-squared test, or a confidence interval for $I^{2}$ ).

\section{Assessment of Reporting Biases}

Prefixed reporting of the outcome was done for checking the reporting bias. 


\section{Data Synthesis}

We used Revman 5.4 for performing statistical analysis and used Risk Ratio (RR)/ Odds Ratio (OR) for estimation of outcome whenever appropriate with $95 \%$ Confident Interval (CI). We used the fixed/random-effects model as per the heterogeneity. We analyzed the MD between the two groups for the duration of virological clearance and length of hospital stay calculated using the median, sample size, and inter-quartile range when mean and standard deviation were not provided in study [52].

\section{Subgroup Analysis and Investigation of Heterogeneity}

For cases of heterogeneity, we used the random effect model, inverse variance, and excluded the study with the most weight.

\section{Sensitivity Analysis}

We excluded the significant outlier studies with the most weight and applied the inverse variance method to assess the effect on the results and re-run the analysis to check for sensitivity analysis.

\section{Results}

A total of 2716 articles were identified after database searching, out of which 477 duplicates were removed. We screened the title and abstracts of 2239 articles and excluded 2156 articles. Full texts of 83 articles were reviewed, and 41 articles were extracted after 42 were excluded with various reasons mentioned in Fig. 1. We included 41 studies for qualitative and 40 studies for quantitative analysis. The qualitative analysis of 41 studies is done in Table 3.

\section{PRISMA 2009 Flow Diagram}

\section{Qualitative Analysis}

Clinical definition

- Mild type: The clinical symptoms are mild, with no abnormal radiological findings

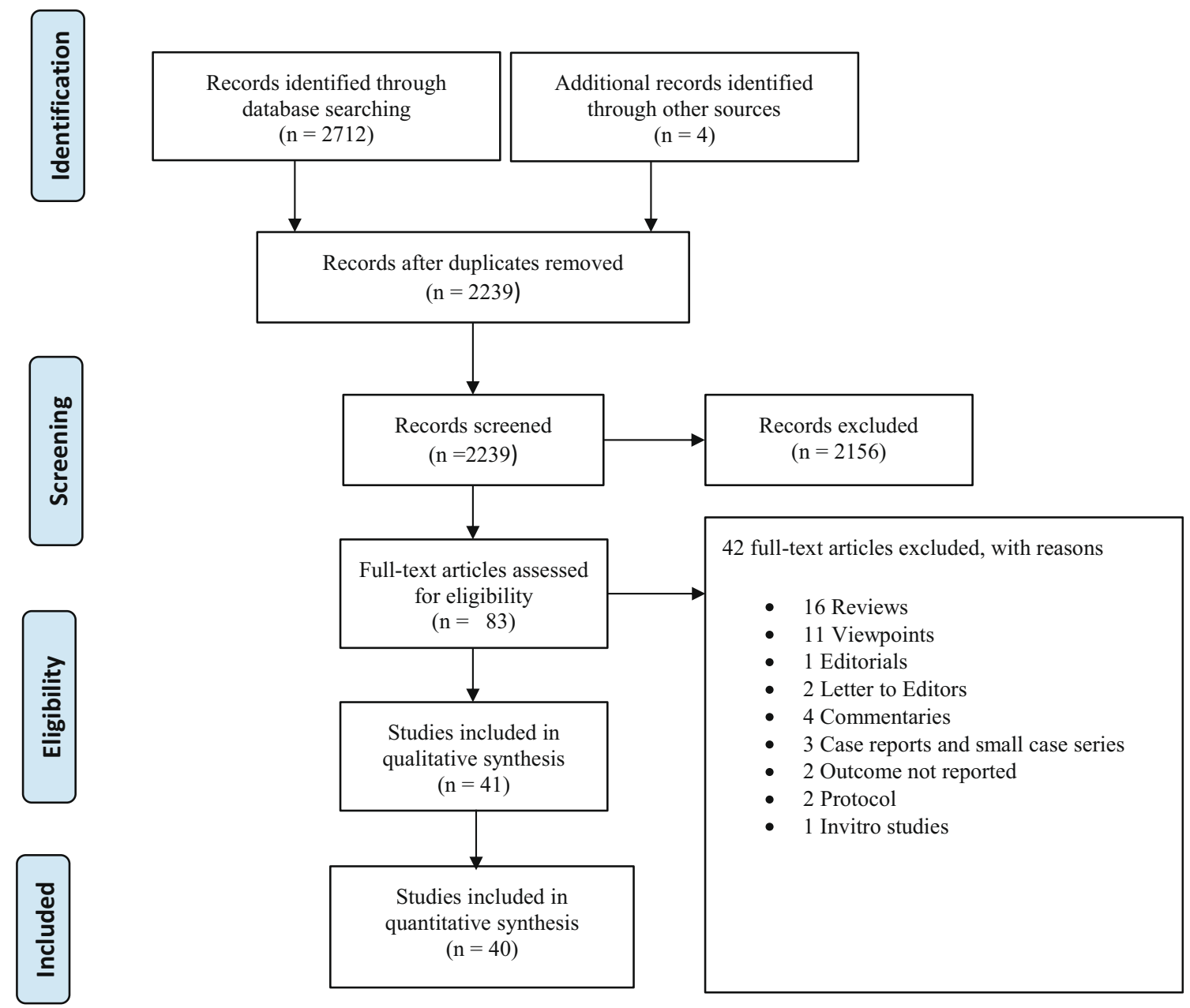

Fig. 1 Flow chart for study design 


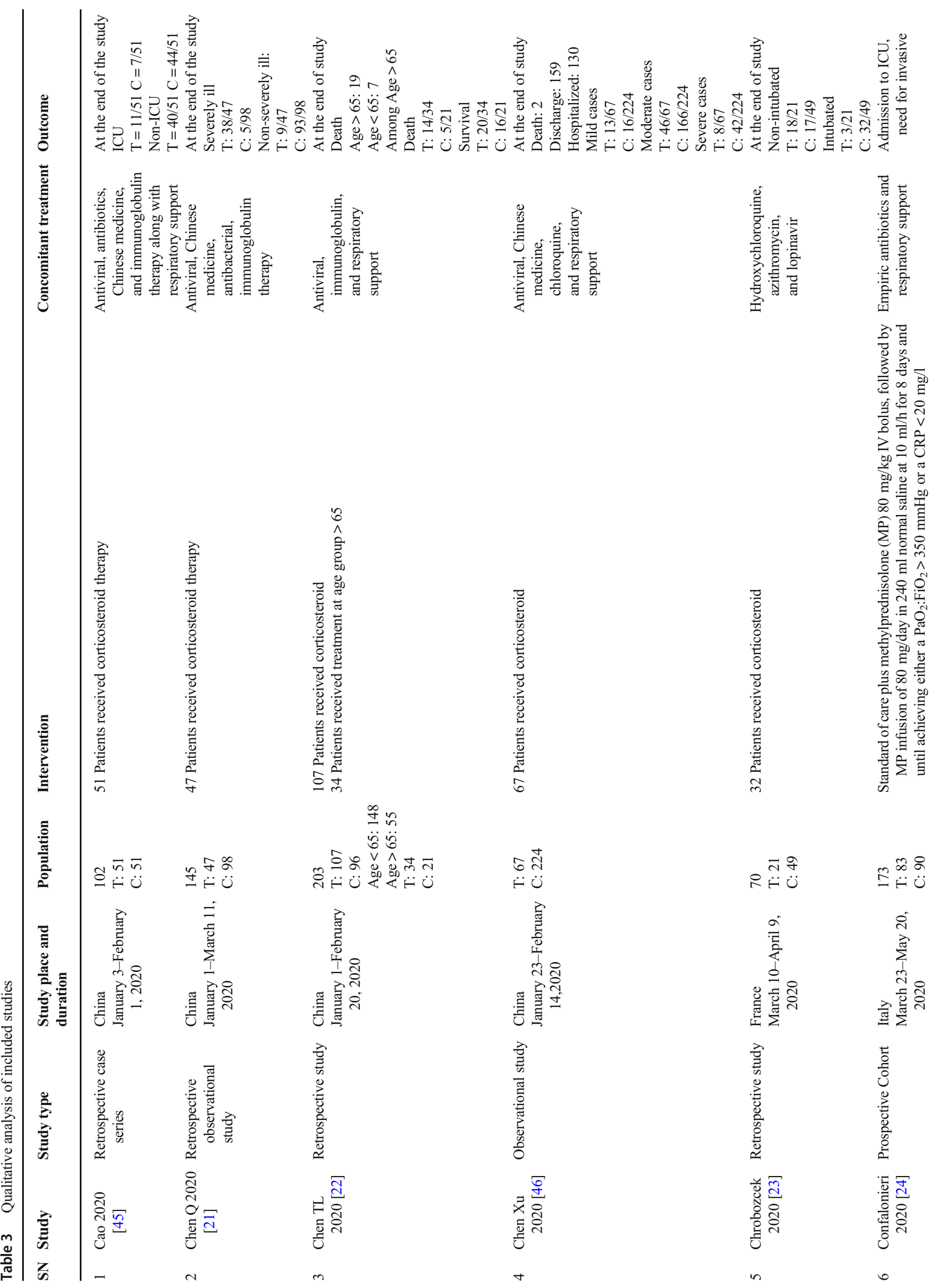



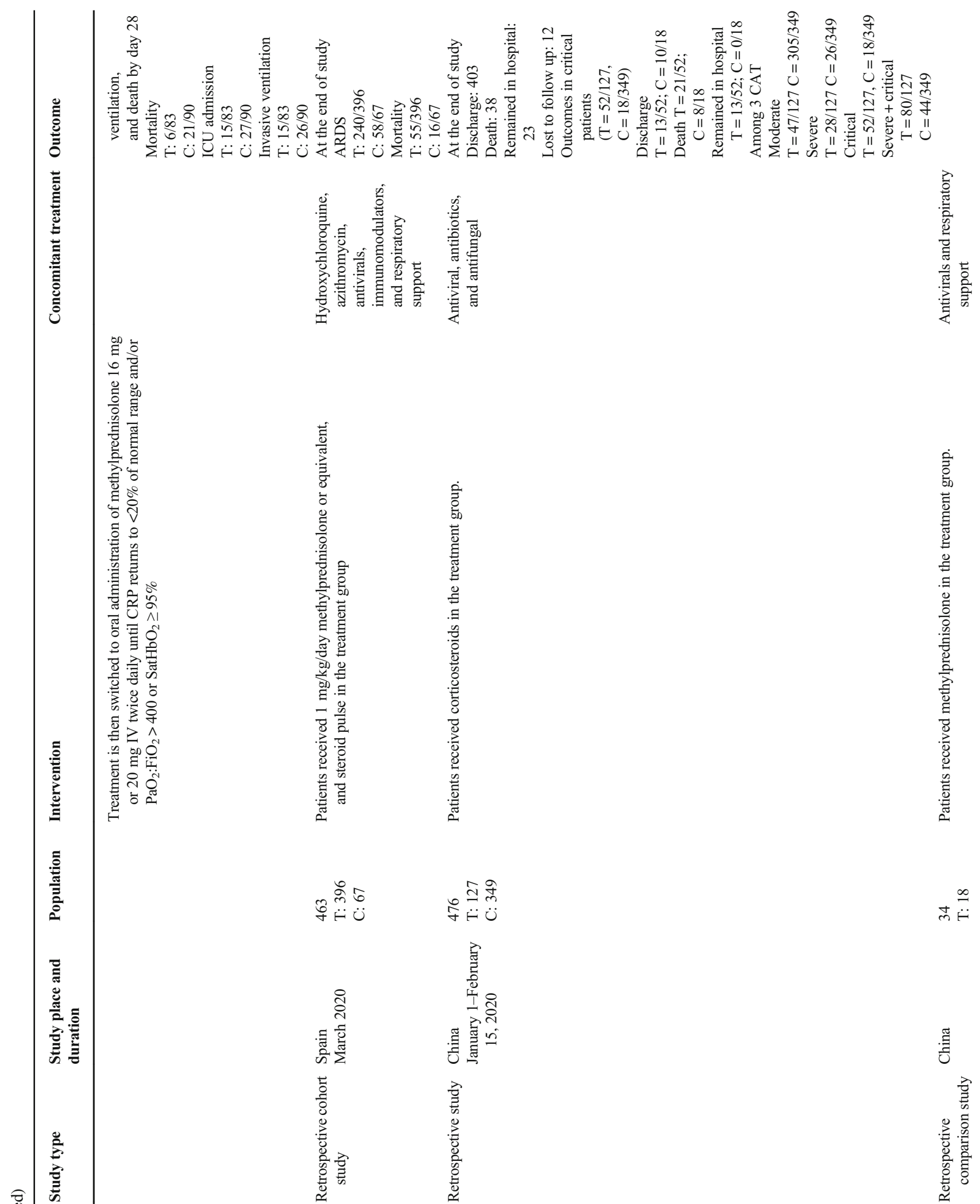

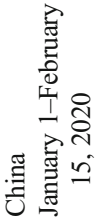

苞

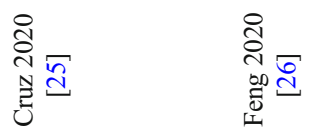




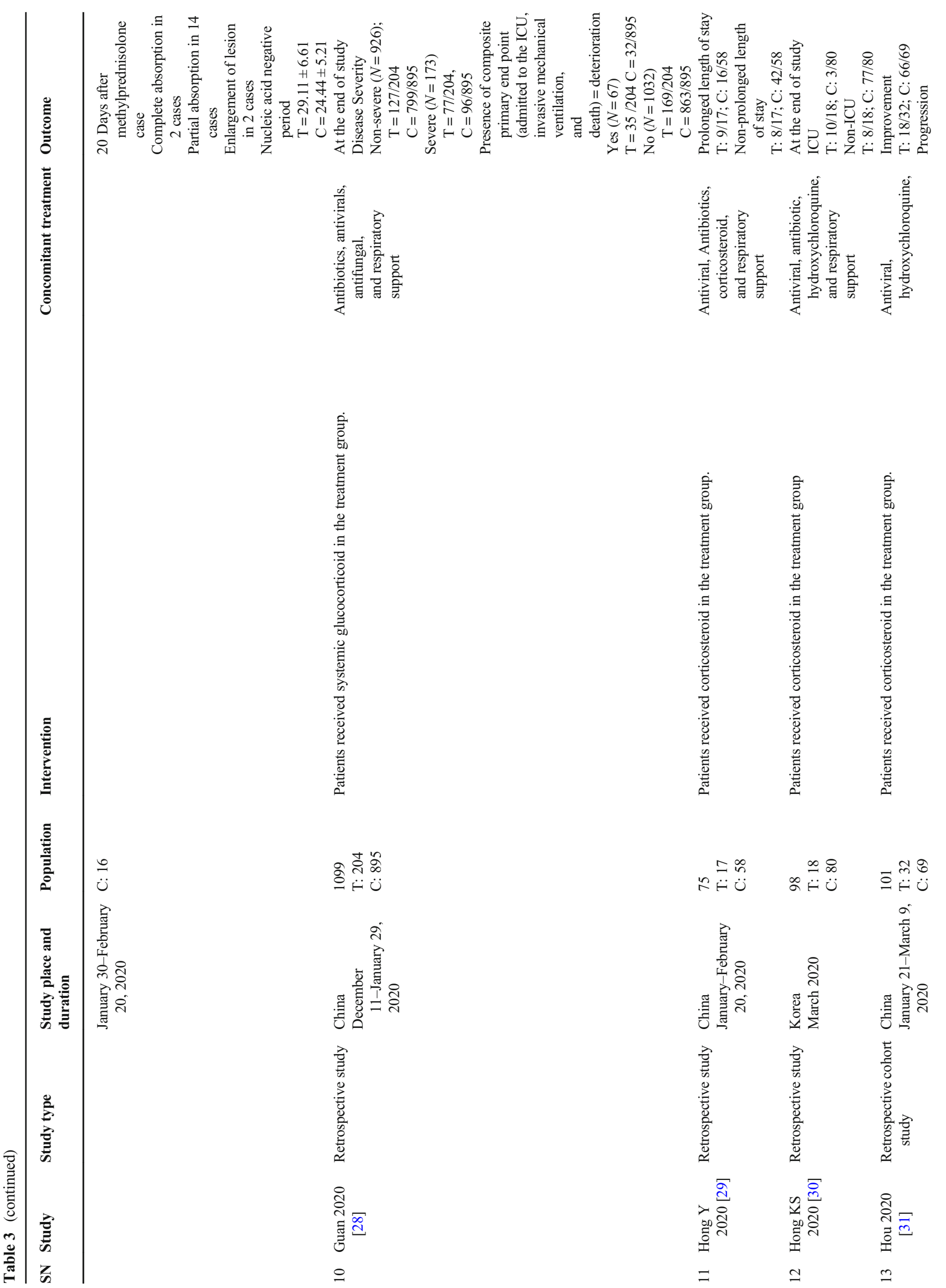




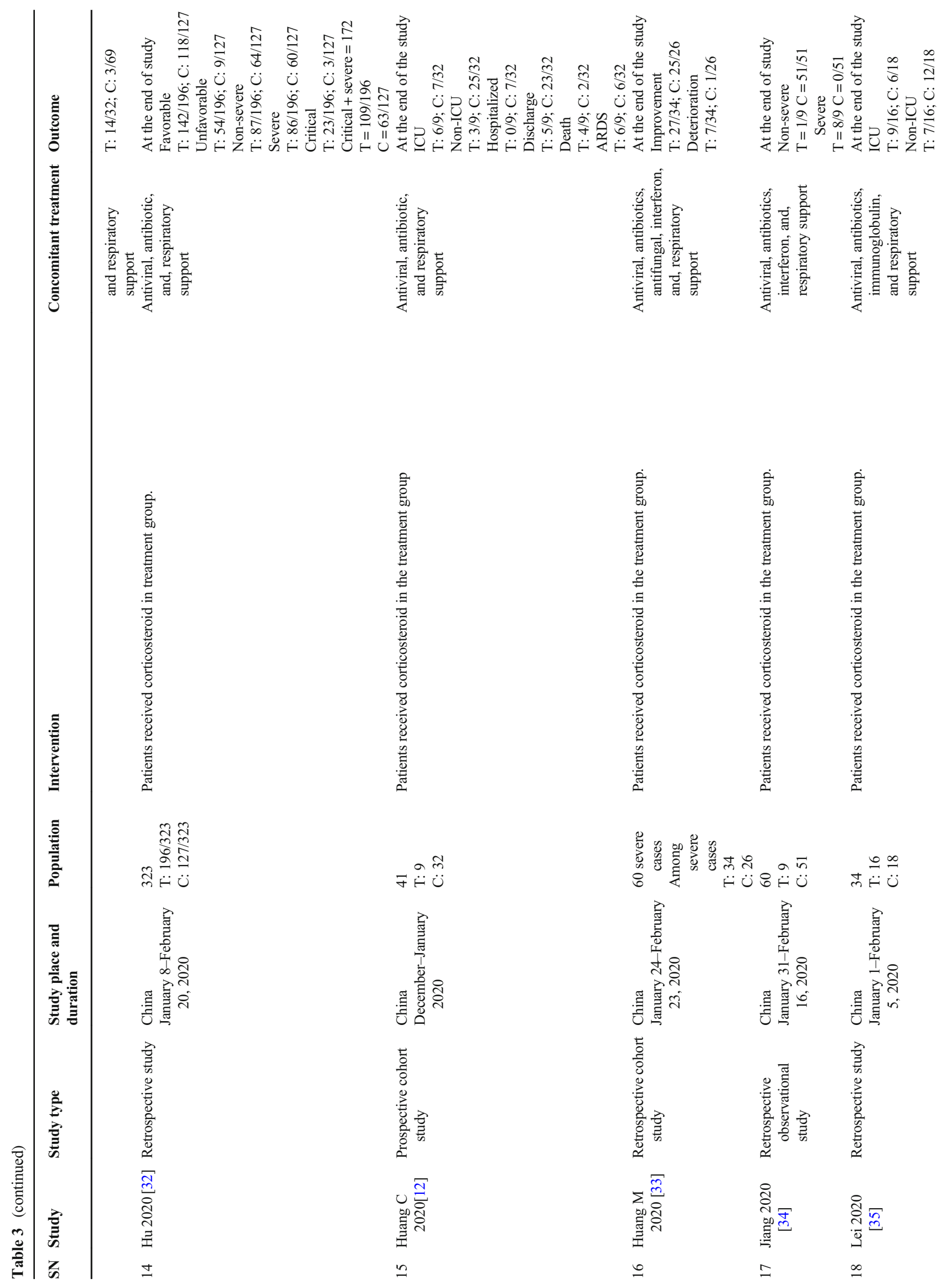




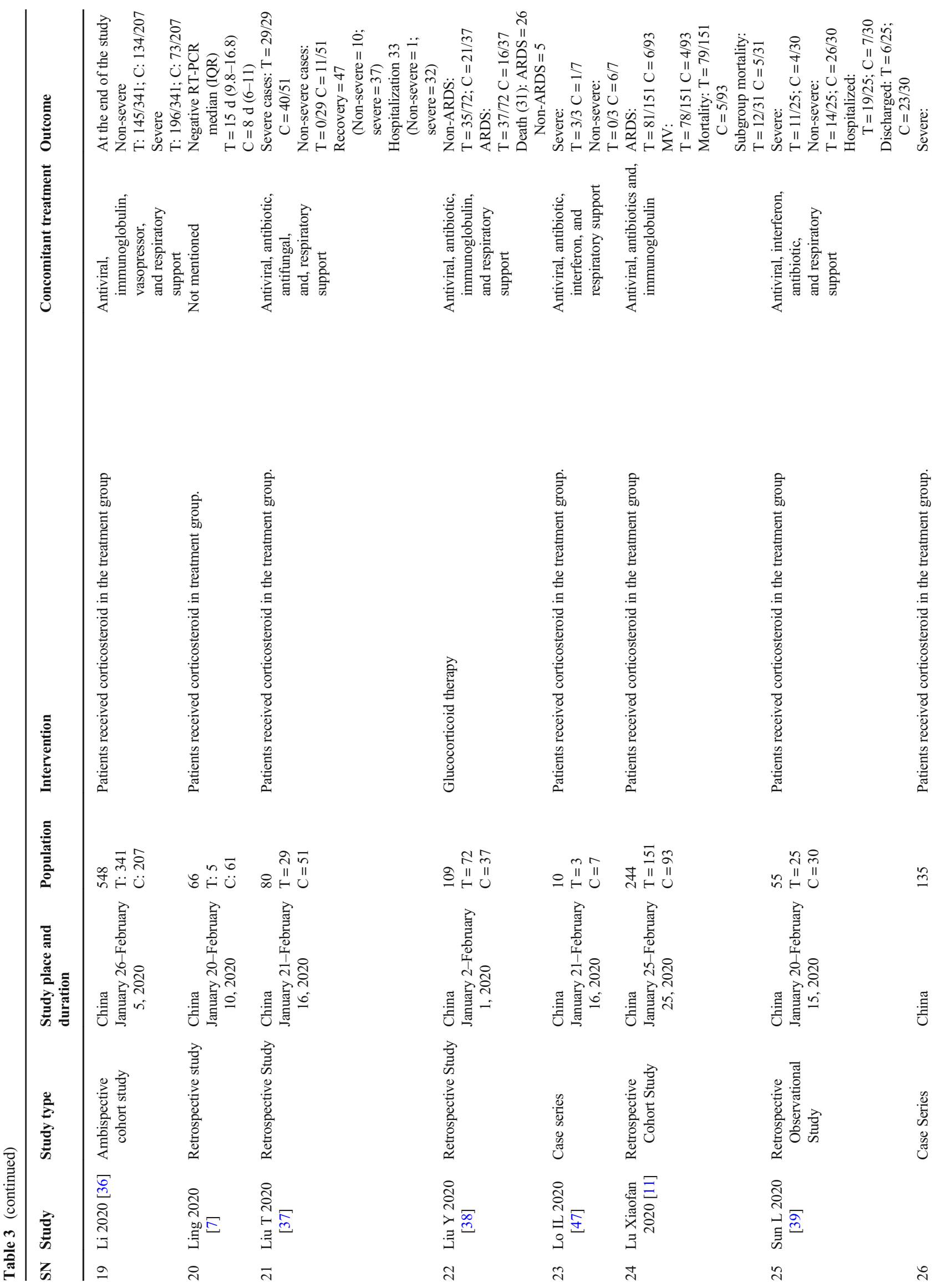




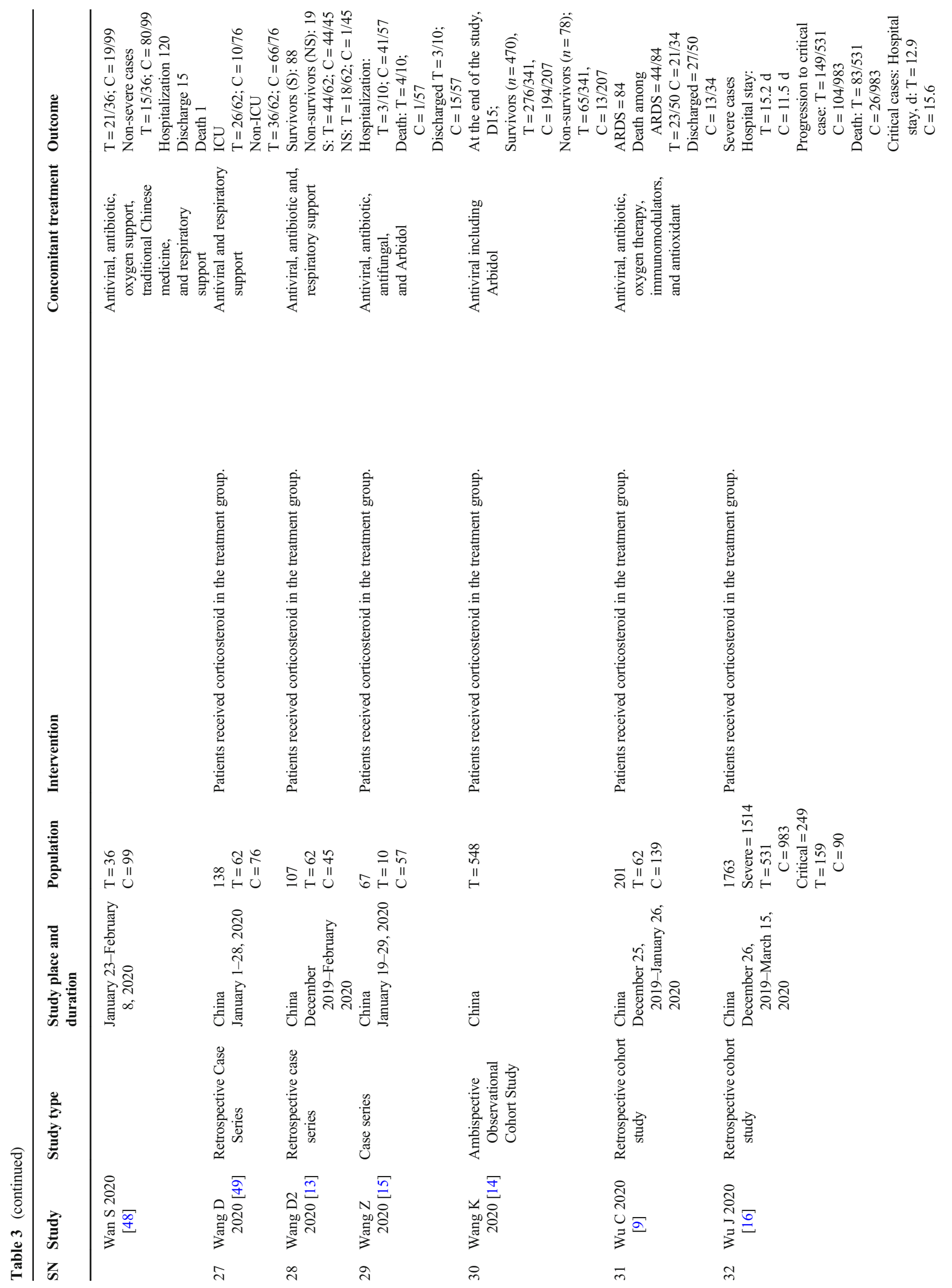




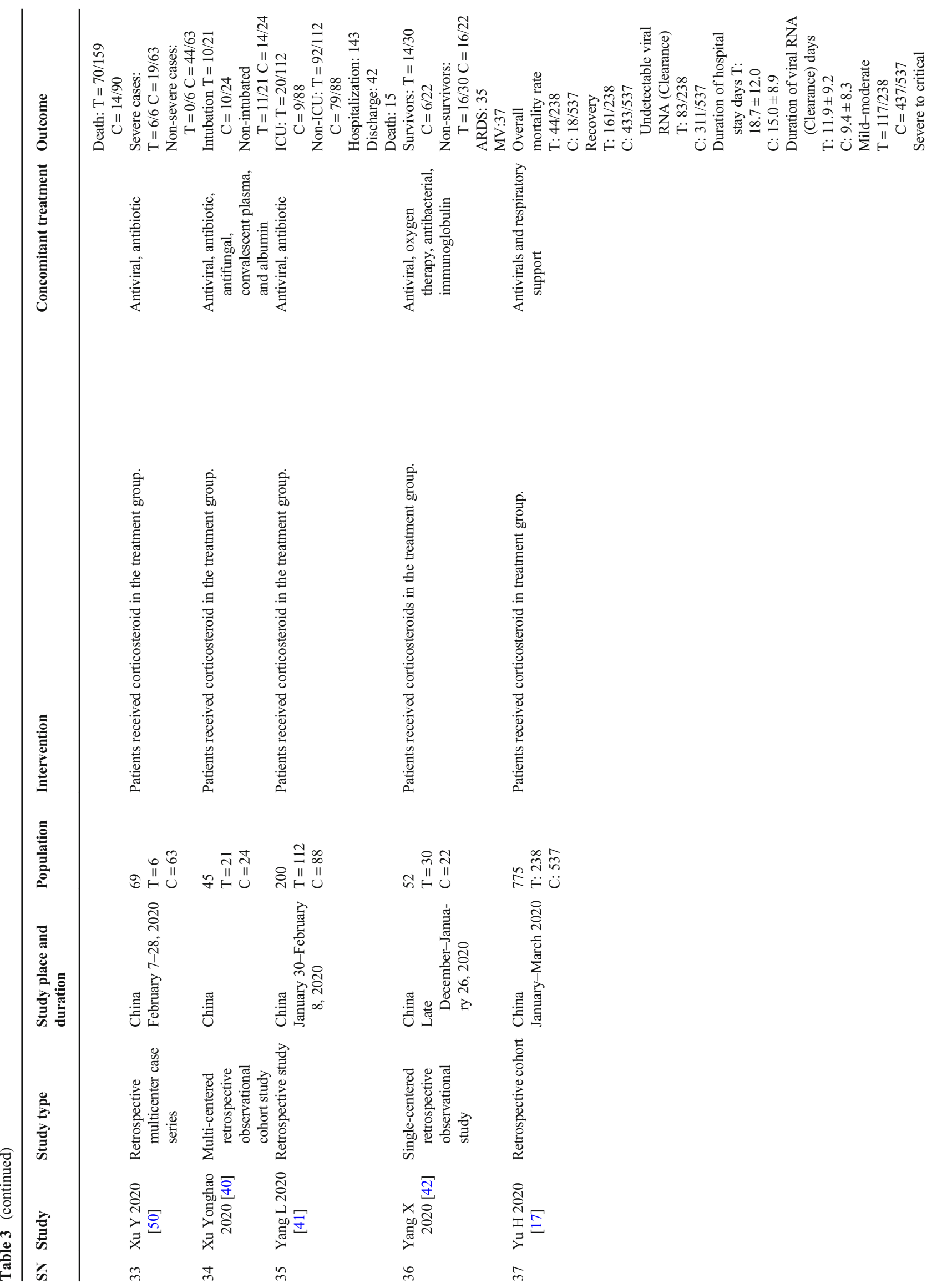




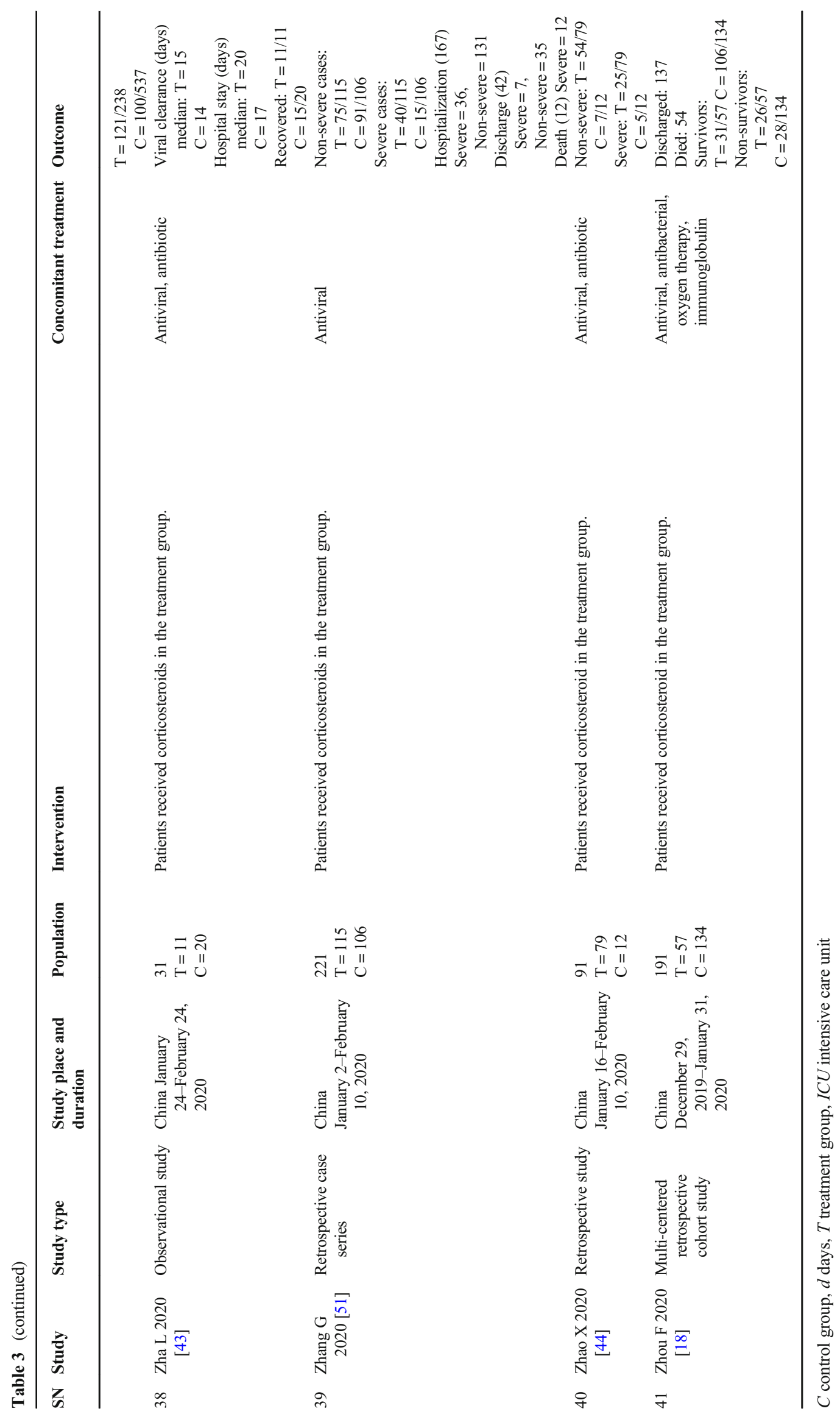


- Moderate type: Fever, cough, and other symptoms are present with pneumonia on chest computed tomography

- Severe type: The disease is classified as severe if one of the following conditions is met such as respiratory distress, respiratory rate $>30 / \mathrm{min}$, oxygen saturation on room air at rest $<93 \%$, and $\mathrm{PaO}_{2} / \mathrm{FiO}_{2}<300$

- Critical type: One of the following conditions has to be met: $d$ respiratory failure occurs and mechanical ventilation is required. $d$ shock occurs. $d$ other organ dysfunction is present, requiring ICU monitoring and treatment

\section{Quantitative Analysis}

Overall, 40 studies included in the quantitative synthesis. There is a constant debate about whether to give corticosteroids or not to COVID-19 individuals. Until now, no proper randomized study showed clear beneficence or harm of giving steroids to COVID-19 patients. In the present meta-analysis, we have compared findings among non-randomized studies to extract the outcome on which a type of patient is prone to get corticosteroids, the overall change in mortality, overall improvement or deterioration among treatment groups in comparison with control, duration of virological clearance, length of hospital stay, the requirement of intubation, and mechanical ventilation.

\section{Who Is More Likely to Get Corticosteroids?}

For this, we did meta-analysis taking all studies comparing severity, baseline/overall ICU admission, and ARDS-diagnosed COVID-19 cases. Among the included studies in the meta-analysis, we found that there is moderate-high heterogeneity, which may be due to clinical and variability in study design and the risk of bias among studies that could not be omitted fully may be due to the acute surge in COVID-19 cases having diversity presenting and getting treatment due to the pandemic.

Severity of COVID Patients The meta-analysis of OR for severe and critical COVID-19 patients tending to get corticosteroids or standard of care compared using random effects model among non-randomized studies showed that there are significant differences between treatment and control arms (OR 4.78, 95\% CI 2.76 to 8.26; participants $=4378$; studies $=15$; $I^{2}=89 \%$ ). Severely ill COVID-19 patients have almost 5 times higher odds of getting corticosteroids during their treatment (Fig. 2). While non-severe individuals are less likely to get corticosteroids during their treatment (OR $0.21,95 \% \mathrm{CI}$ 0.12 to 0.36 ) (Additional file 4/ Fig. 1).
Sensitivity Analysis To evaluate the impact of inverse ORs as well as studies' weight on the meta-analysis results, we conducted sensitivity analyses as according to the substantial relative weight of 4 studies (Yu H 2020 [17], Guan W 2020 [28], Hu L 2020 [32], and Li X 2020 [36]) to the meta-analysis, by excluding these studies as they showed increases in the risk of getting steroid in treatment than observed (OR 7.64, 95\% CI 2.85 to 20.43) (Additional file 4/ Figs. 2 and 3).

ICU Admitted COVID Patients Among studies comparing ICU admitted with non-ICU patients, overall odds for corticosteroids in addition to SOC are approximately 4 (OR 4.09, 95\% CI 1.89 to 8.84; participants $=613$; studies $=6 ; I^{2}=64 \%$ ) (Fig. 3). While non-ICU patients are having lesser odds for getting corticosteroids (OR 0.24, 95\% CI 0.11 to 0.53 ) (Additional file 4/ Fig. 4).

COVID Patients with ARDS Our meta-analysis among studies reporting ARDS and non-ARDS showed about 3 (OR $2.99,95 \%$ CI 0.66 to 13.64 ; participants $=1632$; studies $=$ $5 ; I^{2}=95 \%$ ) times the odds of getting corticosteroids but it is of no significance statistically (Fig. 4). Sensitivity assessment done after excluding a study with significantly high weight (Cruz AF 2020 [25]) showed significant odds for getting corticosteroids among ARDS (OR 5.64, 95\% CI 2.02 to 15.70) (Additional file 4/ Fig. 5). Similar assessments among non-ARDS individuals showed nonARDS have lower odds of getting steroids (OR 0.18, 95\% CI 0.06 to 0.49) (Additional file 4/ Fig. 6).

\section{Corticosteroids in Addition to Standard of Care: Mortality}

The meta-analysis of death outcome among non-randomized studies with or without complete follow-ups showed significantly higher mortality risk with corticosteroids and standard of care group compared with standard of care alone (RR 2.01, $95 \%$ CI 1.12 to 3.63; participants $=4451$; studies $=14 ; I^{2}=$ 92\%; RD 0.10, 95\% CI 0.02 to 0.17 ) (Fig. 5). Survival assessment among COVID-19 individuals with or without corticosteroids showed no survival benefits after adding corticosteroids, rather corticosteroid addition may decrease the survival rate (RR $0.88,95 \%$ CI 0.78 to 0.98 ) (Additional file 4/ Fig. 7).

Sensitivity Analysis for Corticosteroids in Addition to SOC on Mortality Compared with SOC Alone To evaluate the impact of inverse RRs as well as studies' weight on the meta-analysis results, we conducted sensitivity analyses excluding $\mathrm{Wu} \mathrm{J}$ 2020 [16] due to its substantial weight in the meta-analysis. Excluding Wu J 2020 [16] showed no significant changes (RR 1.76, 95\% CI 1.03 to 3.02) (Additional file 4/ Figs. 8 and 9). 
Corticosteroids in Addition to Standard of Care: Discharge

Corticosteroids in Addition to Standard of Care in Studies

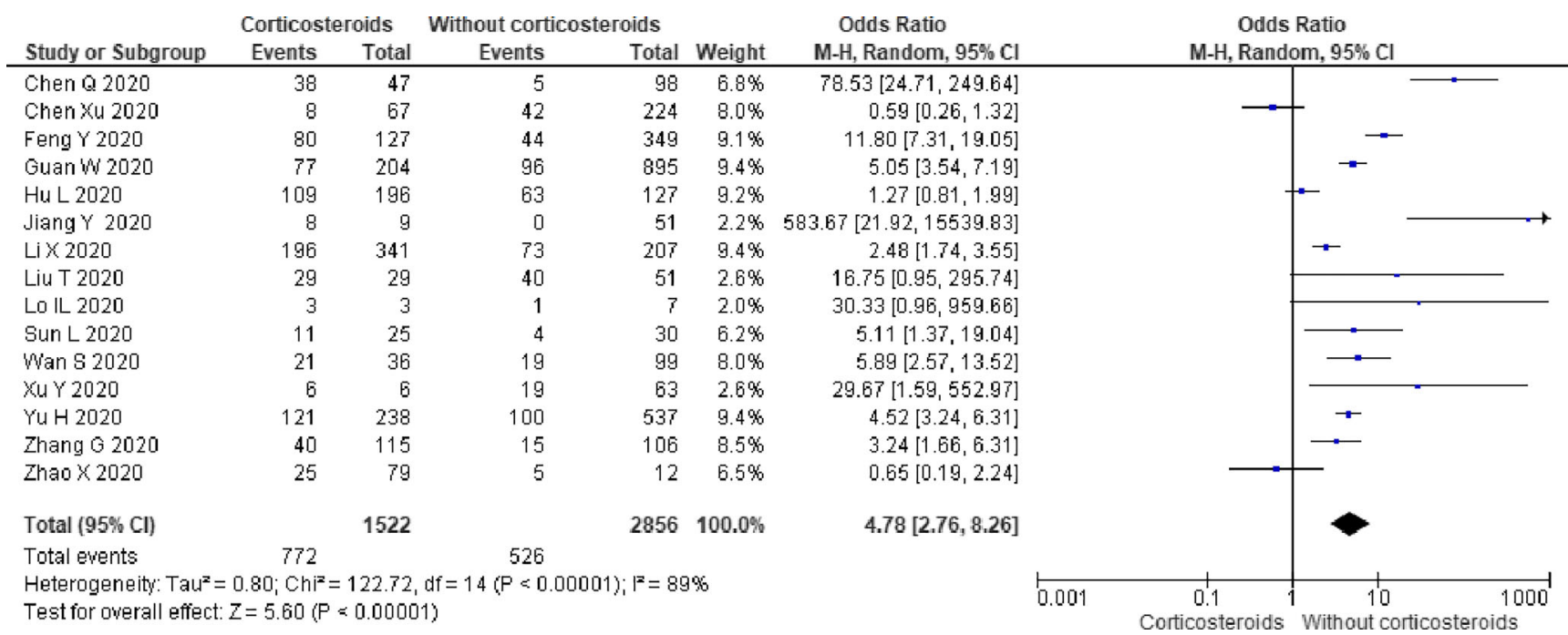

Fig. 2 Forest plot for odds ratios among severe and critically ill COVID-19 patient

\section{Rate}

The meta-analysis on discharge rate as an outcome among nonrandomized studies with or without complete follow-ups showed a significant lower discharge rate with corticosteroids and standard of care group compared with standard of care alone at the point of data analysis of study included for analysis (RR $0.79,95 \%$ CI 0.63 to 0.99 ; participants $=1390$; studies $=9 ; I^{2}=$ $62 \%, \mathrm{RD}-0.13,95 \% \mathrm{CI}-0.26$ to -0.01 ) (Fig. 6).

\section{Corticosteroids in Addition to Standard of Care in Studies with Incomplete Follow-Up: Hospitalization at the Point of Concluding Studies}

The meta-analysis on hospitalization rate at the point of concluding studies including studies with incomplete follow-up, showed no significant differences between treatment and control groups (RR $1.28,95 \%$ CI 0.27 to 6.17 ) (Fig. 7).

\section{with Incomplete Follow-Up: On Recovery/Improvement}

The meta-analysis on recovery/improvement rate at the point of concluding studies including studies with incomplete follow-up results showed significant delay in recovery/ improvement among the treatment groups with added corticosteroids to SOC $($ OR $0.24,95 \%$ CI 0.13 to 0.43 ; participants $=$ 2555 ; studies $\left.=9 ; I^{2}=71 \%\right)$ (Fig. 8). Rather, additional corticosteroids with SOC showed significant odds of deterioration (OR 3.79, 95\% CI 1.93 to 7.46) (Additional file 4/ Fig. 10).

\section{Corticosteroids in Addition to Standard of Care: Intubation and Mechanical Ventilation}

Meta-analysis on overall mechanical ventilation among the included non-randomized studies showed no significant differences between corticosteroids and SOC versus SOC only about the odds of mechanical ventilation during treatment $(\mathrm{OR} 1.44,95 \%$ CI 0.35 to 5.92 ; participants $=$ 684; studies $=7 ; I^{2}=90 \%$ ) (Fig. 9).

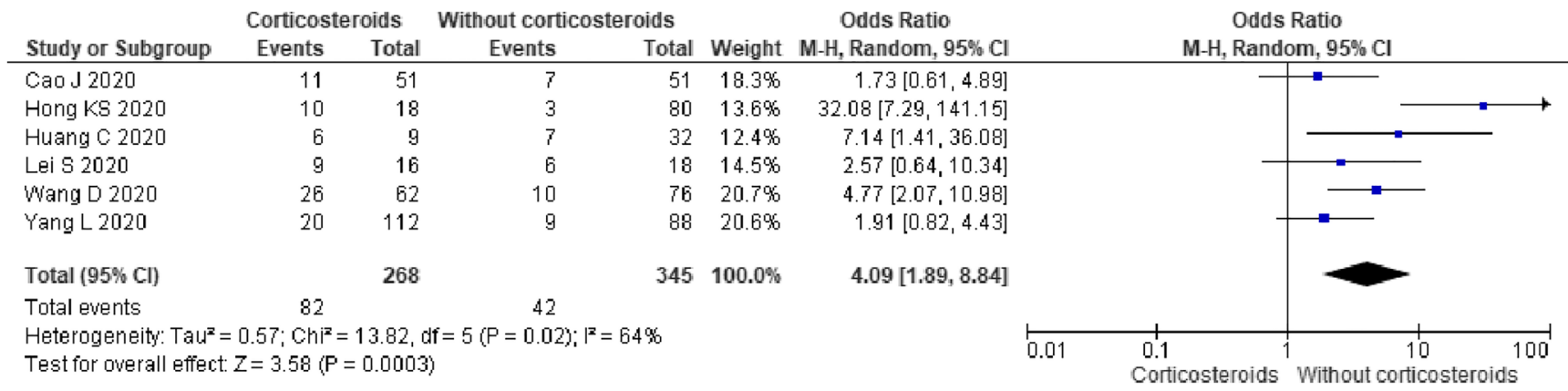

Fig. 3 Forest plot for odds ratios regarding getting corticosteroids among ICU-admitted patient 


\begin{tabular}{|c|c|c|c|c|c|c|c|c|}
\hline \multirow[b]{2}{*}{ Study or Subgroup } & \multicolumn{2}{|c|}{ Corticosteroids } & \multicolumn{2}{|c|}{ Without orticosteroids } & \multirow[b]{2}{*}{ Weight } & \multirow{2}{*}{$\begin{array}{l}\text { Odds Ratio } \\
\text {, Random, } 95 \% \mathrm{Cl}\end{array}$} & \multirow{2}{*}{\multicolumn{2}{|c|}{$\begin{array}{c}\text { Odds Ratio } \\
\text { M- } \mathrm{H} \text {, Random, } 95 \% \mathrm{Cl}\end{array}$}} \\
\hline & Events & Total & Events & Total & & & & \\
\hline Cruz AF 2020 & 240 & 396 & 58 & 67 & $20.7 \%$ & $0.24[0.11,0.50]$ & $=-$ & \\
\hline Huang c 2020 & 6 & 9 & 6 & 32 & $17.3 \%$ & $8.67[1.67,44.94]$ & & \\
\hline Liu Y 2020 & 37 & 72 & 16 & 37 & $20.5 \%$ & $1.39[0.62,3.08]$ & & \\
\hline Lu Xlaofan 2020 & 81 & 151 & 6 & 93 & $20.2 \%$ & $16.78[6.91,40.73]$ & & \\
\hline Yu H 2020 & 64 & 238 & 31 & 537 & $21.3 \%$ & $6.00[3.78,9.53]$ & & \\
\hline Total $(95 \% \mathrm{Cl})$ & & 866 & & 766 & $100.0 \%$ & $2.99[0.66,13.64]$ & & \\
\hline Total events & 428 & & 117 & & & & & \\
\hline $\begin{array}{l}\text { Heterogeneity: Tau } \\
\text { Test for owerall effect }\end{array}$ & $\begin{array}{l}2.76 ; \mathrm{Chi}^{2} \\
\mathrm{Z}=1.42 \Leftrightarrow \mathrm{P}\end{array}$ & $\begin{array}{l}5.25,0 \\
0.16)\end{array}$ & $f=4(P<0.0$ & $\left.\right|^{2}=95$ & & & $\begin{array}{ll}0.01 & 0.1 \\
\text { Without cortic }\end{array}$ & Cortico \\
\hline
\end{tabular}

Fig. 4 Forest plot for odds ratios regarding getting corticosteroids among COVID-19 with ARDS patient

\section{Length of Hospital Stay (LoHS)}

Meta-analysis comparing the overall length of hospital stay between treatment and control groups showed approximately 4 days longer stay among treatments with corticosteroids (MD in days 4.19, 95\% CI 2.57 to 5.81; participants $=2726$; studies $\left.=4 ; I^{2}=70 \%\right)($ Fig. 10).

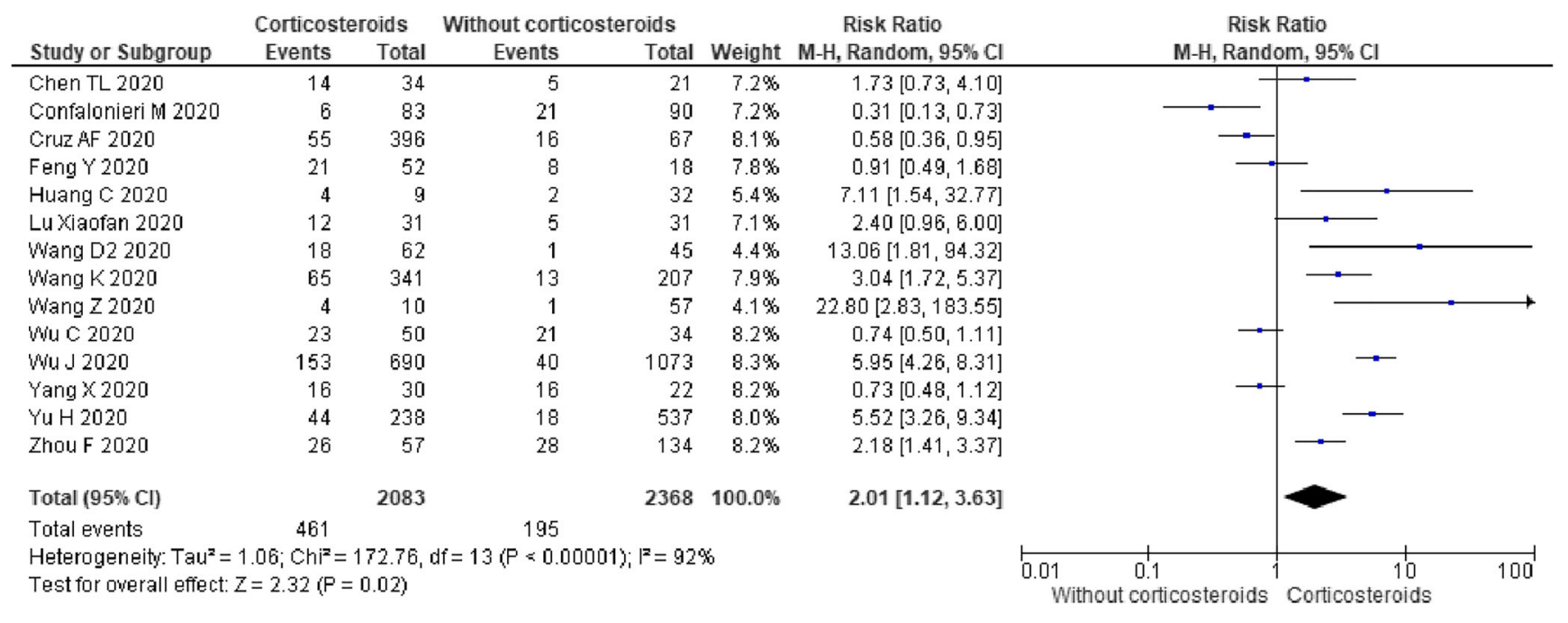

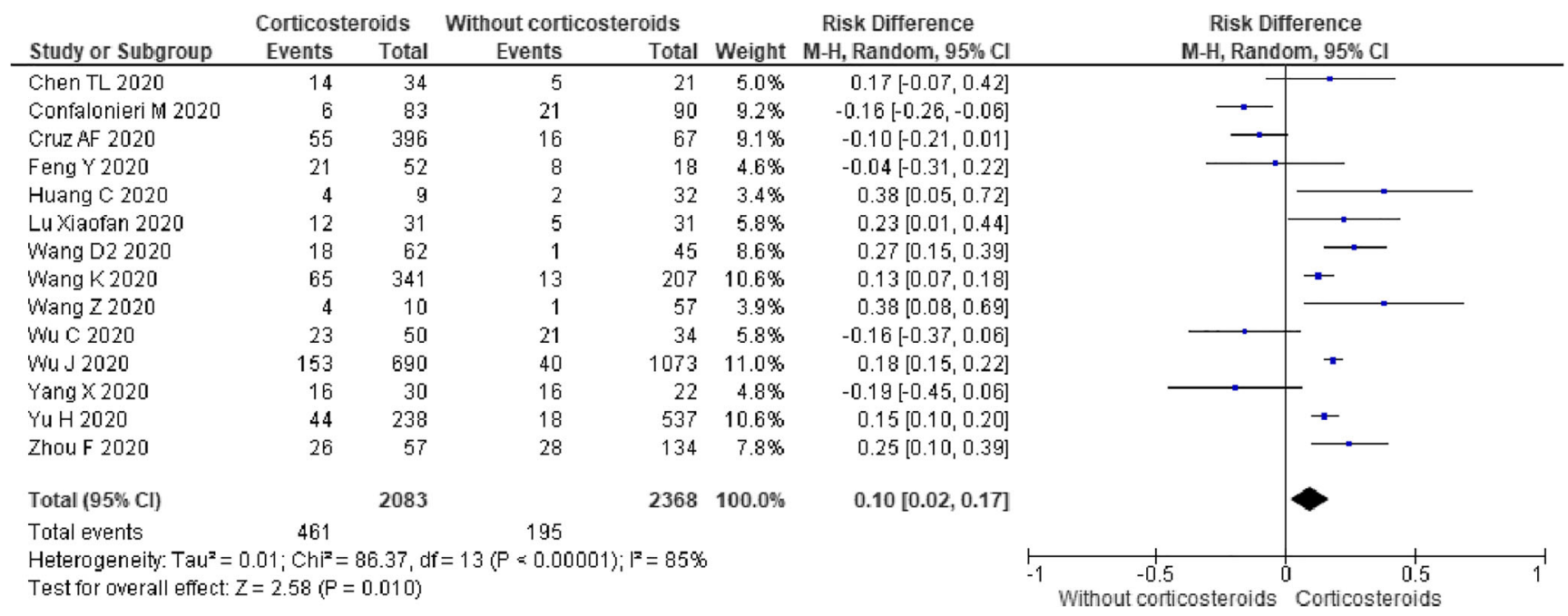

Fig. 5 Forest plot for risk ratios and risk differences regarding corticosteroids with SOC on mortality compared with SOC alone 


\begin{tabular}{|c|c|c|c|c|c|c|c|c|c|}
\hline \multirow[b]{2}{*}{ Study or Subgroup } & \multicolumn{2}{|c|}{ Corticosteraids } & \multicolumn{2}{|c|}{ Without corticosteroids } & \multirow[b]{2}{*}{ Weight } & \multirow{2}{*}{$\begin{array}{l}\text { Risk Ratio } \\
\text { M-H, Random, } 95 \% \mathrm{Cl}\end{array}$} & \multirow{2}{*}{\multicolumn{2}{|c|}{$\begin{array}{c}\text { Risk Ratio } \\
\text { M-H, Random, } 95 \% \mathrm{Cl} \\
\end{array}$}} & \\
\hline & Events & Total & Events & Total & & & & & \\
\hline Chen TL 2020 & 20 & 34 & 16 & 21 & $14.5 \%$ & $0.77[0.53,1.12]$ & & - & \\
\hline Feng $Y 2020$ & 13 & 52 & 10 & 18 & $8.3 \%$ & $0.45[0.24,0.84]$ & & & \\
\hline Huang C 2020 & 5 & 9 & 23 & 32 & $8.4 \%$ & $0.77[0.41,1.44]$ & & & \\
\hline Sun L 2020 & 6 & 25 & 23 & 30 & $6.8 \%$ & $0.31[0.15,0.65]$ & & & \\
\hline Wang $Z 2020$ & 3 & 10 & 15 & 57 & $3.9 \%$ & $1.14[0.40,3.23]$ & & & \\
\hline Wu C 2020 & 27 & 50 & 13 & 34 & $10.9 \%$ & $1.41[0.86,2.32]$ & & & \\
\hline Yang $\times 2020$ & 14 & 30 & 6 & 22 & $6.1 \%$ & $1.71[0.78,3.74]$ & & & \\
\hline Yu H 2020 & 161 & 238 & 433 & 537 & $22.8 \%$ & $0.84[0.76,0.92]$ & - & & \\
\hline Zhou F 2020 & 31 & 57 & 106 & 134 & $18.3 \%$ & $0.69[0.53,0.89]$ & & & \\
\hline Total $(95 \% \mathrm{Cl})$ & & 505 & & 885 & $100.0 \%$ & $0.79[0.63,0.99]$ & & & \\
\hline Total events & 280 & & 645 & & & & & & \\
\hline \multicolumn{7}{|c|}{$\begin{array}{l}\text { Heterogeneity: Tau }=0.05 ; \mathrm{Ch}^{2}=20.90, \mathrm{df}=8(\mathrm{P}=0.007) ; \mathrm{I}^{2}=62 \% \\
\text { Test for overall effect: } Z=2.08(\mathrm{P}=0.04)\end{array}$} & $\begin{array}{lc}0.2 & 0.5 \\
\text { Without corticosteroids }\end{array}$ & Corticoste & 5 \\
\hline
\end{tabular}

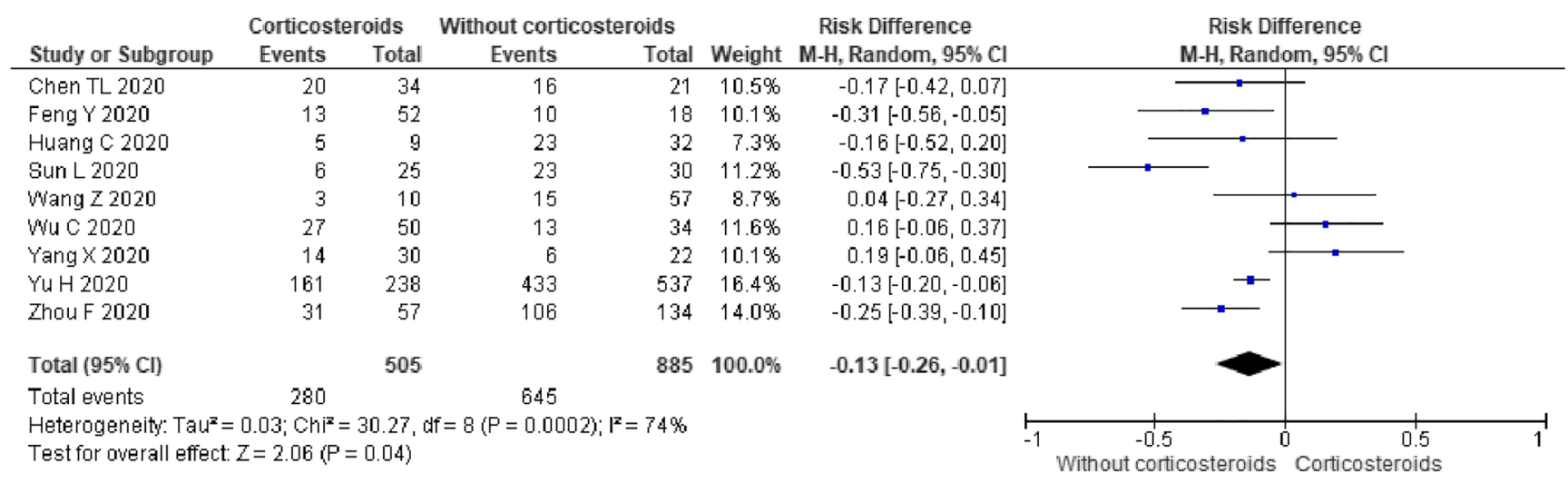

Fig. 6 Forest plot for risk ratios and risk differences regarding corticosteroids with SOC on discharge rate compared with SOC alone

\section{Duration to Convert Negative RT-PCR}

Our meta-analysis on negative conversion of RT-PCR demonstrated approximately 3 days (MD 2.42, 95\% CI 1.31 to 3.53 ; participants $=906$; studies $=4 ; I^{2}=14 \%$ ) more on treatment with corticosteroid than without corticosteroids (Fig. 11).

\section{Clinical Trials}

There are right away 37 trials (details in additional file 5) registered for evaluation regarding the use of corticosteroids on COVID-19 [53]. Among these, 3 trials are already completed, while 9 trials are not yet recruiting participants. A total of 24 such trials are in recruiting status. These trials are run in different parts of the world. According to the location provided for the 33 trials, most of these are being managed in France (11 trials), followed by Spain ( 5 trials). A total of twenty-eight trials are of observational trials, and the rest are of an interventional type. Corticosteroids like prednisolone, methylprednisolone, dexamethasone, budesonide are used as drugs in such trials. Ranging from 12 participants in a trial conducted in Belgium, some trials are enrolling 12,000 participants in the UK to 13,770 in France. One trial among registered trials is in the active phase but not in the recruiting status.

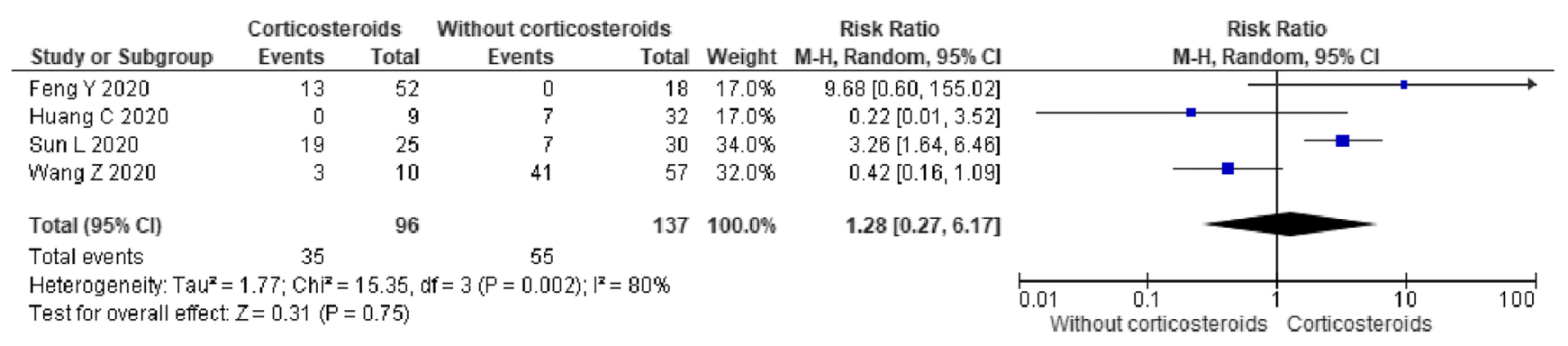

Fig. 7 Forest plot for risk ratios regarding corticosteroids with SOC for hospitalization 


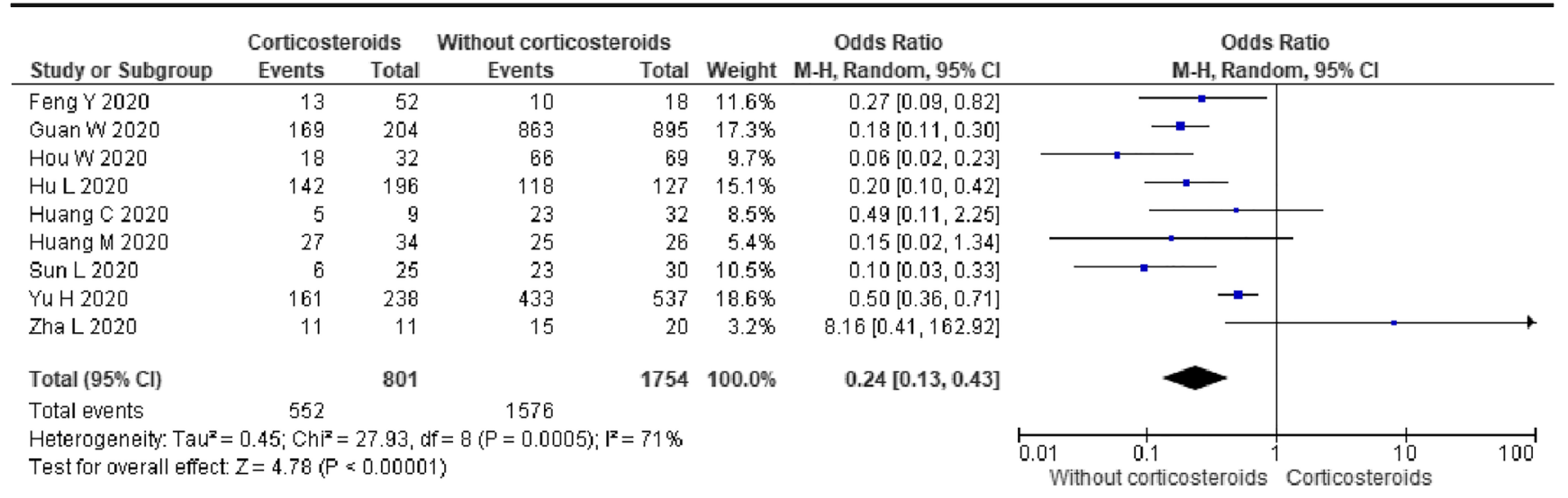

Fig. 8 Forest plot for odds ratios regarding corticosteroids with SOC on recovery/improvement

\section{Discussion}

The debate about how safe it is to use corticosteroids in critically ill patients is ongoing for many decades. The pathophysiology of previous coronavirus infectious outbreaks like SARS-CoV and MERS-CoV and the use of corticosteroids for treatment are still unclear. Earlier studies show that the increased amount of pro-inflammatory cytokines in serum was found in patients with SARS-CoV/MERS-CoV infections $[54,55]$. Thus, the common ground of genetic homology might have attracted the clinician's attention to repurposing the drug in the treatment of ongoing COVID-19 pandemic. In this meta-analysis, we assessed which patients with COVID19 are more likely to get corticosteroids in addition to standard of care and compared their outcomes including mortality, risk of intubation, viral clearance, recovery, hospital stay, and overall improvement compared with the standard of care alone.
The quantitatively synthesized data and their evaluation led to many significant findings. Critical patients and severely ill COVID-19 cases were likely to get the drug as the odds were almost 5 times higher in the treatment arm compared with the control arm (OR 4.78, 95\% CI 2.69 to 8.48). ICU-admitted patients have higher odds of getting the drug as there was a significant difference between the ICU and non-ICU patients (OR 4.09, 95\% CI 1.89 to 8.84). Among patients with ARDS, the odds were significantly higher following sensitivity analysis (OR 5.56, 95\% CI 2.00 to 15.45), and non-ARDS patients showed lower odds of getting corticosteroids in their treatment (OR $0.18,95 \%$ CI 0.06 to 0.50 ). As per the outcomes analyzed, there were few surprising findings regarding mortality caused by the drug. An earlier study showed that corticosteroids might decrease the risk of death in COVID-19 patients $[9,56,57]$ but our meta-analysis derived contradicting answers. Higher mortality risk was observed with statistically significant numbers among the corticosteroid group, while

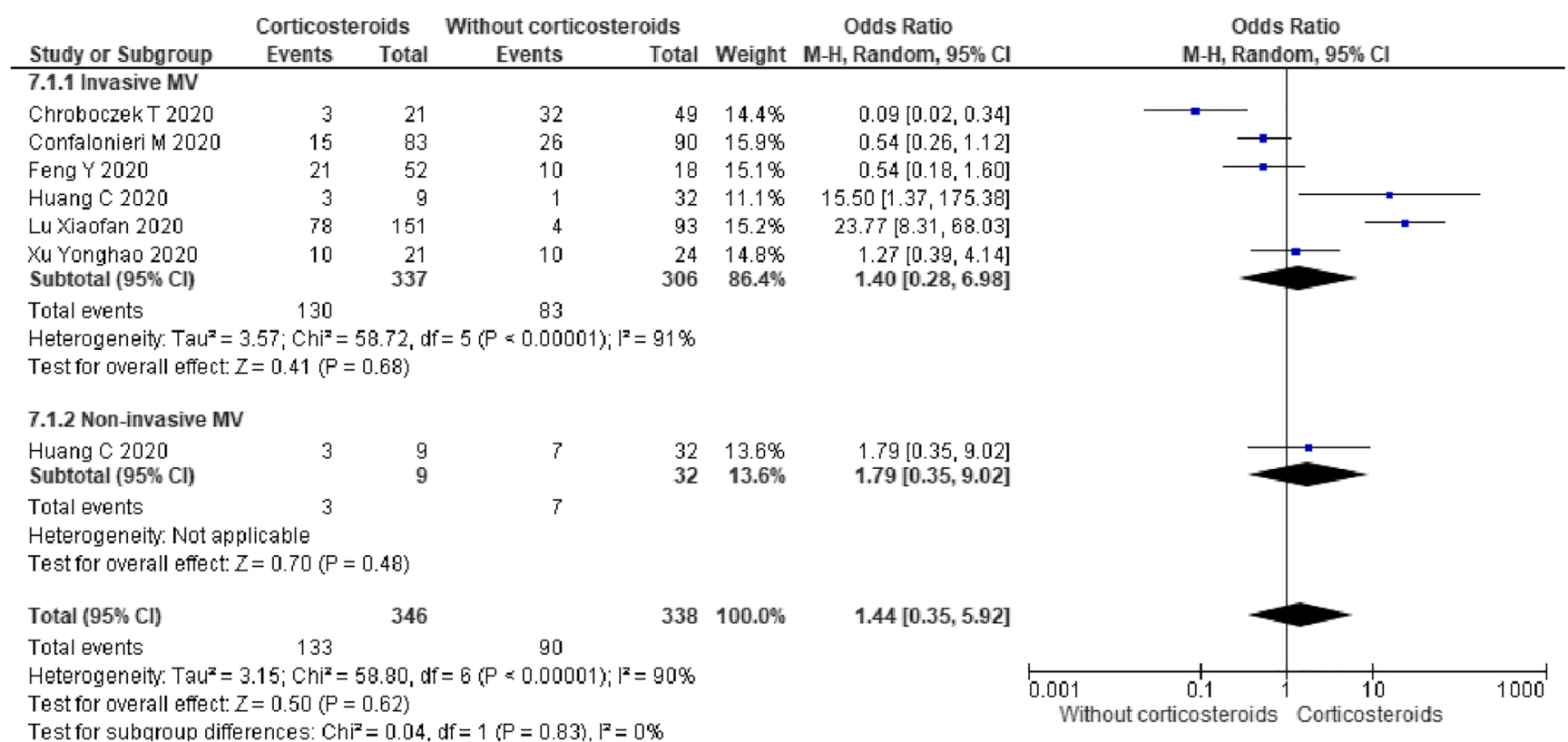

Fig. 9 Forest plot of corticosteroids in addition to standard of care on intubation and mechanical ventilation compared with SOC alone 


\begin{tabular}{|c|c|c|c|c|c|c|c|c|c|c|c|c|}
\hline \multirow[b]{2}{*}{ Study or Subgroup } & \multicolumn{3}{|c|}{ Corticosteroids } & \multicolumn{3}{|c|}{ Without corticosteroids } & \multirow[b]{2}{*}{ Weight } & \multirow{2}{*}{$\begin{array}{l}\text { Mean Difference } \\
\text { IV, Random, } 95 \% \mathrm{Cl}\end{array}$} & \multirow{2}{*}{\multicolumn{3}{|c|}{$\begin{array}{l}\text { Mean Difference } \\
\text { IV, Random, } 95 \% \mathrm{Cl}\end{array}$}} & \\
\hline & Mean & SD & Total & Mean & SD & Total & & & & & & \\
\hline Feng $Y 2020$ & 23.763 & 11.3382 & 75 & 16.0518 & 8.1903 & 331 & $18.2 \%$ & T.T1 [5.00, 10.42] & & & $\rightarrow-$ & \\
\hline Mแ J 2020 & 16.0759 & 10.9271 & 531 & 12.0953 & 8.0922 & 983 & $32.1 \%$ & $3.98[2.92,5.04]$ & & & $-\frac{1}{2}$ & \\
\hline Yu H 2020 & 18.7 & 12 & 238 & 15 & 8.9 & 537 & $26.4 \%$ & $3.70[2.00,5.40]$ & & & - & \\
\hline Zha L 2020 & 19.6323 & 2.5447 & 11 & 17.3597 & 3.1914 & 20 & $23.3 \%$ & $2.27[0.22,4.33]$ & & & - & \\
\hline Total $(95 \% \mathrm{Cl})$ & & & 855 & & & 1871 & $100.0 \%$ & $4.19[2.57,5.81]$ & & & & \\
\hline \multicolumn{9}{|c|}{$\begin{array}{l}\text { Heterogeneity: } \text { Tau }^{2}=1.83 ; \mathrm{Ch}^{2}=10.02, \mathrm{df}=3(\mathrm{P}=0.02) ; \mathrm{I}^{2}=70 \% \\
\text { Test for overall effect: } Z=5.07(\mathrm{P}=0.00001)\end{array}$} & -20 & $\begin{array}{ll}-10 \\
\text { ticosteroids }\end{array}$ & Without $\mathrm{Co}$ & $\begin{array}{c}20 \\
\text { steroids }\end{array}$ \\
\hline
\end{tabular}

Fig. 10 Forest plot of corticosteroids in addition to standard of care on length of hospital stay

comparison was done between the treatment and control arm (RR 2.01, 95\% CI 1.12 to 3.63) along with no survival benefit in the treatment group. Our meta-analysis alarms an increased risk of mortality among severe and critically ill COVID-19 patients and guides against the rampant use of corticosteroids in COVID-19 patients based on the present level of evidence.

The duration of viral clearance and length of hospital stay was higher in the treatment group as the result showed days required for conversion of RT-PCR to become negative took 3 days more in the treatment arm (MD in days; 2.70, 95\% CI 1.03 to 4.37), and the patient in the treatment arm stayed 5 days longer in the hospital (MD 5.42, 95\% CI 3.56 to 7.28). The discharge rate after the most studies was lower in the treatment group (RR 0.79, 95\% CI 0.63 to 0.99 ), but there was no significant difference between the hospitalization rate of patients in the treatment and control arm (RR 0.80, 95\% CI 0.33 to 1.94). Results showed delayed recovery among treatment groups (OR 0.24 , 95\% CI 0.13 to 0.43 ), although there was no significant difference between the cases in the two groups being mechanically ventilated or intubated (OR 1.44, 95\% CI 0.35 to 5.92). Although metaanalysis in the past has extracted a similar result in the context of benefit, virus clearance, and hospitalization [58], the result regarding mortality may become a groundbreaking finding.

The overall mortality rate among ICU and severely critically ill patients is already higher irrespective of the disease condition. Our analysis of studies among COVID-19 patients showed getting corticosteroids in their treatment is higher in ICU and severely critically ill COVID-19 cases. Our main findings from the reported study raised questions towards the current practice of using corticosteroids in such a group of patients. Though the non-randomized nature of the included study and risk of bias is there, we need to rethink the use of corticosteroid in such COVID-19 patients because of no added benefit rather than having a poor outcome.
There are multiple trials going on around the world focusing on the efficacy of corticosteroid among cases of COVID19 and the use of corticosteroid has been considered to be default $[59,60]$. The WHO welcomed the results of the clinical trial in the UK which showed decreased mortality with dexamethasone in both patients requiring ventilator and on oxygen therapy [61]. Despite the optimism from WHO about the preliminary findings of the Oxford trial, there are doubts among clinicians which can only be answered as more clinical trials are completed and their results are analyzed.

\section{Strength and Limitations of the Meta-Analysis}

This meta-analysis has pooled data from 40 studies done among cases of COVID-19 solely. The sample size was remarkably increased with decreased probability of making Type II error in the study. The study has focused on the groups more likely to be treated with corticosteroids. Moreover, there were significant results under outcomes, which are an appreciable achievement regarding the current situation with inadequate evidence regarding the drug's use. The study has conducted subgroup analysis wherever applicable along with weighing out and sensitivity analysis for all outcomes which makes the results reliable.

Limitations of the study need to be acknowledged as there has been bias in many forms. There is moderate-to-high heterogeneity as various types of studies with methodological and clinical diversity were added to the pool; the dosing of the drug has not been uniform, and although the study has significant results, a cause-effect relationship cannot be derived in hands. Almost all studies have been conducted in China, which might affect the applicability to people with different ethnicity, and many variations of the drug efficacy and side effects have not been explored. This is why more controlled studies should be

\begin{tabular}{lrrrrrrrrr} 
& \multicolumn{3}{c}{ Corticosteroids } & \multicolumn{3}{c}{ Without corticosteroids } & \multicolumn{2}{c}{ Mean Difference } \\
Study or Subgroup & Mean & SD & Total & Mean & SD & Total & Weight & IV, Fixed, 95\% Cl & Mean Difference \\
IV, Fixed, 95\% Cl
\end{tabular}

Fig. 11 Forest plot of corticosteroids in addition to standard of care on negative conversion of RT-PCR 
dedicated to back up the use of this drug, being most of the studies for which we did meta-analysis were of retrospective observational type. To strengthen this result, the results of ongoing RCTs need to be explored when it will come out.

\section{Conclusion}

Our study concludes that more severe and critically ill patients tend to get corticosteroids, and the mortality risk increases with the use of corticosteroids. There were no survival benefits with the use of corticosteroids along with delayed recovery and longer hospital stay; this may be due to the tendency that more severe patients get corticosteroids. Corticosteroids have been effectively used for a long time in the field of medicine and in unprecedented times like these; little evidence of efficacy should be dealt with meticulously. Ongoing trials may answer unexplored questions about their safety and efficacy in the near future.

Acknowledgments Initially, this meta-analysis was submitted in Systematic Reviews; one of the title of Springer Nature but after completing the peer review process, they advise to transfer to $\mathrm{SN}$ Comprehensive Clinical Medicine. During prior submission, Systematic Reviews sent our manuscript to preprint to disseminate our findings as earlier as possible to the scientific community.

Availability of Data and Materials The datasets used and analyzed during the current study are available from the corresponding author on reasonable request.

Authors' Contributions PB and DBS contributed in the concept and design, analysis, and interpretation of data. ER and SK contributed in the literature search, data extraction, and review and assisted in analysis.

All authors were involved in drafting and revising the manuscript and approved the final version.

\section{Compliance with Ethical Standards}

Competing Interests The authors declare that they have no competing interests.

\section{Ethics Approval and Consent to Participate Not applicable}

Consent for Publication Not applicable

Abbreviations ARDS, Acute respiratory distress syndrome; C, Control group; CI, Confident interval; COVID-19, Coronavirus disease; d, Days; ICU, Intensive care unit; $\mathrm{I}^{2}$, I-squared; LoHS, Length of hospital stay (LoHS); MD, Mean differences; MERS-CoV, Middle East respiratory syndrome coronavirus; NF- $\mathrm{kB}$, Nuclear transcription factor- $\mathrm{kB}$; NHLBI, National Heart, Lung, and Blood Institute; OR, Odds ratio; PRISMA, Preferred reporting items for systematic reviews and metaanalyses; RCTs, Randomized controlled trials; RD, Risk difference; RR, Risk ratio; RT-PCR, Reverse transcription-polymerase chain reaction; SARS-CoV, Severe acute respiratory syndrome coronavirus; SOC, Standard of care; T, Treatment group; WHO, World Health Organization

\section{References}

1. Coronavirus (COVID-19) [Internet]. WHO. 2020 [cited 2020 Jun 13]. Available from: https://who.sprinklr.com/. Accessed 13 Jun 2020

2. Cruz-Topete D, Cidlowski JA. One hormone, two actions: anti- and pro-inflammatory effects of glucocorticoids. Neuroimmunomodulation. 2014;22(0):20-32.

3. Stern A, Skalsky K, Avni T, Carrara E, Leibovici L, Paul M. Corticosteroids for pneumonia. Cochrane Database Syst Rev. 2017;12(12):CD007720. https://doi.org/10.1002/14651858. CD007720.pub3.

4. Rhen T, Cidlowski JA. Anti-inflammatory action of glucocorticoids - new mechanisms for old drugs. N Engl J Med. 2005;353(16): 1711-23.

5. Yin-Chun Yam L, Chun-Wing Lau A, Yuk-Lin Lai F, Shung E, Chan J, Wong V. Corticosteroid treatment of severe acute respiratory syndrome in Hong Kong. J Inf Secur. 2007;54(1):28-39.

6. Russell CD, Millar JE, Baillie JK. Clinical evidence does not support corticosteroid treatment for 2019-nCoV lung injury. Lancet. 2020;395:473-5. https://doi.org/10.1016/S0140-6736(20)30317-2 (Lancet Publishing Group).

7. Ling $\mathrm{Y}, \mathrm{Xu}$ S-B, Lin $\mathrm{Y}-\mathrm{X}$, Tian D, Zhu Z-Q, Dai F-H, et al. Persistence and clearance of viral RNA in 2019 novel coronavirus disease rehabilitation patients. Chin Med J (Engl) [Internet]. 2020;133(9):1039-43 Available from: https://pubmed.ncbi.nlm. nih.gov/32118639. Accessed 13 June 2020.

8. Bai Y, Yao L, Wei T, Tian F, Jin D-Y, Chen L, et al. Presumed asymptomatic carrier transmission of COVID-19. JAMA [Internet]. 2020;323(14):1406-7 Available from: https://doi.org/10.1001/ jama.2020.2565.

9. Wu C, Chen X, Cai Y, Xia J, Zhou X, Xu S, Risk factors associated with acute respiratory distress syndrome and death in patients with coronavirus disease, et al. pneumonia in Wuhan, China. JAMA. Intern Med. 2019;2020. https://doi.org/10.1001/jamainternmed. 2020.0994 .

10. Liu K, Fang Y-Y, Deng Y, Liu W, Wang M-F, Ma J-P, et al. Clinical characteristics of novel coronavirus cases in tertiary hospitals in Hubei Province. Chin Med J (Engl) [Internet]. 2020;133(9): 1025-31 Available from: https://pubmed.ncbi.nlm.nih.gov/ 32044814. Accessed 13 June 2020.

11. Lu X, Chen T, Wang Y, Wang J, Yan F. Adjuvant corticosteroid therapy for critically ill patients with COVID-19. Crit Care [Internet]. 2020;24(1):241 Available from: https://doi.org/10. 1186/s13054-020-02964-w.

12. Huang C, Wang Y, Li X, Ren L, Zhao J, Hu Y, et al. Clinical features of patients infected with 2019 novel coronavirus in Wuhan, China. Lancet. 2020;395(10223):497-506.

13. Wang D, Yin Y, Hu C, Liu X, Zhang X, Zhou S, et al. Clinical course and outcome of 107 patients infected with the novel coronavirus, SARS-CoV-2, discharged from two hospitals in Wuhan, China. Crit Care [Internet]. 2020;24(1):188 Available from: https://doi.org/10.1186/s13054-020-02895-6.

14. Wang K, Zhang Z, Yu M, Tao Y, Xie M. 15-day mortality and associated risk factors for hospitalized patients with COVID-19 in Wuhan, China: an ambispective observational cohort study. Intensive Care Med [Internet]. 2020;46:1472-4. https://doi.org/10. 1007/s00134-020-06047-w.

15. Wang Z, Yang B, Li Q, Wen L, Zhang R. Clinical features of 69 cases with coronavirus disease 2019 in Wuhan, China. Clin Infect Dis [Internet]. 2020;71:769-77. Available from: https://doi.org/10. $1093 / \mathrm{cid} / \mathrm{ciaa} 272$.

16. Wu J, Huang J, Zhu G, Liu Y, Xiao H, Zhou Q, et al. Systemic corticosteroids show no benefit in severe and critical COVID-19 patients in Wuhan, China: a retrospective cohort study [Internet]. 
medRxiv. 2020. Available from: https://doi.org/10.1101/2020.05. 11.20097709.

17. Yu H, Li P-J, Wang T, Yao R, Ni Z, Yang H, et al. Can corticosteroids improve the outcomes of patients with Covid-19? A retrospective cohort study of patients within and outside the epicentre [Internet]. Res Square. 2020. Available from: https://doi.org/10. 21203/rs.3.rs-32279/v1.

18. Zhou F, Yu T, Du R, Fan G, Liu Y, Liu Z, et al. Clinical course and risk factors for mortality of adult inpatients with COVID-19 in Wuhan, China: a retrospective cohort study. Lancet (London, England). 2020;395(10229):1054-62.

19. Liberati A, Altman DG, Tetzlaff J, Mulrow C, Gøtzsche PC, Ioannidis JP, et al. The PRISMA statement for reporting systematic reviews and meta-analyses of studies that evaluate health care interventions: explanation and elaboration. Ann Intern Med. 2009;151(4):W-65.

20. Study Quality Assessment Tools [Internet]. National Heart, Lung, and Blood Institute (NHLBI). 2020. https://doi.org/10.1007/ s15010-020-01432-5.

21. Chen Q, Zheng Z, Zhang C, Zhang X, Wu H, Wang J, et al. Clinical characteristics of 145 patients with corona virus disease 2019 (COVID-19) in Taizhou, Zhejiang, China. Infection [Internet]. 2020;48:543-51. https://doi.org/10.1007/s15010-020-01432-5.

22. Chen T, Dai Z, Mo P, Li X, Ma Z, Song S, et al. Clinical characteristics and outcomes of older patients with coronavirus disease 2019 (COVID-19) in Wuhan, China: a single-centered, retrospective study. J Gerontol A Biol Sci Med Sci [Internet] Available from: 2020. https://doi.org/10.1093/gerona/glaa089.

23. Chroboczek T, Lacoste M, Wackenheim C, Challan-Belval T, Amar B, Boisson T, et al. Beneficial effect of corticosteroids in severe COVID-19 pneumonia: a propensity score matching analysis. medRxiv [Internet]. 2020; Available from: http://medrxiv.org/ content/early/2020/05/13/2020.05.08.20094755.abstract.

24. Methylprednisolone for patients with COVID-19 severe acute respiratory syndrome (MP-C19) [Internet]. NIH U.S. National Library of Medicine. 2020 [cited 2020 Jun 12]. Available from: https://clinicaltrials.gov/ct2/show/NCT04323592. Accessed 13 June 2020.

25. Fernandez-Cruz A, Ruiz-Antoran B, Munoz-Gomez A, SanchoLopez A, Mills-Sanchez P, Centeno-Soto GA, et al. Impact of glucocorticoid treatment in SARS-COV-2 infection mortality: a retrospective controlled cohort study [Internet]. medRxiv; 2020. Available from: https://doi.org/10.1101/2020.05.22.20110544

26. Feng Y, Ling Y, Bai T, Xie Y, Huang J, Li J, et al. COVID-19 with different severities: a multicenter study of clinical features. Am J Respir Crit Care Med. 2020;201(11):1380-8.

27. Gong Y, Guan L, Jin Z, Chen S, Xiang G, Gao B. Effects of methylprednisolone use on viral genomic nucleic acid negative conversion and CT imaging lesion absorption in COVID-19 patients under 50 years old. J Med Virol [Internet]. 2020. https://doi. org/10.1002/jmv.26052 Available from: https://pubmed.ncbi.nlm. nih.gov/32441786.

28. Guan W, Ni Z, Hu Y, Liang W, Ou C, He J, et al. Clinical Characteristics of Coronavirus Disease 2019 in China. N Engl J Med [Internet]. 2020;382(18):1708-20. Available from. https:// doi.org/10.1056/NEJMoa2002032.

29. Hong Y, Wu X, Qu J, Gao Y, Chen H, Zhang Z. Clinical characteristics of coronavirus disease 2019 and development of a prediction model for prolonged hospital length of stay. Ann Transl Med. 2020;8(7):443.

30. Hong KS, Lee KH, Chung JH, Shin KC, Choi EY, Jin HJ, et al. Clinical features and outcomes of 98 patients hospitalized with SARS-CoV-2 infection in Daegu, South Korea: a brief descriptive study. Yonsei Med J [Internet]. 2020;61(5):431-7 Available from: https://pubmed.ncbi.nlm.nih.gov/32390367. Accessed 13 June 2020
31. Hou W, Zhang W, Jin R, Liang L, Xu B, Hu Z. Risk factors for disease progression in hospitalized patients with COVID-19: a retrospective cohort study. Infect Dis (Auckl) [Internet]. 2020;52(7): 498-505. Available from: https://doi.org/10.1080/23744235.2020. 1759817.

32. $\mathrm{Hu} \mathrm{L}$, Chen $\mathrm{S}, \mathrm{Fu} \mathrm{Y}$, Gao Z, Long H, Ren H, et al. Risk factors associated with clinical outcomes in 323 COVID-19 patients in Wuhan, China. medRxiv [Internet]. 2020;2020.03.25.20037721. Available from: http://medrxiv.org/content/early/2020/03/30/2020. 03.25.20037721.abstract. Accessed 13 June 2020.

33. Huang M, Yang Y, Shang F, Zheng Y, Zhao W, Luo L, et al. Early and critical care in severe patients with COVID-19 infection in Jiangsu Province, China: a descriptive study [Internet]. Res Square. 2020. Available from: https://doi.org/10.21203/rs.3.rs$17397 / \mathrm{v} 1$.

34. Jiang Y, He S, Zhang C, Wang X, Chen X, Jin Y, et al. Clinical characteristics of 60 discharged cases of 2019 novel coronavirusinfected pneumonia in Taizhou, China. Ann Transl Med. 2020;8(8):547.

35. Lei S, Jiang F, Su W, Chen C, Chen J, Mei W, et al. Clinical characteristics and outcomes of patients undergoing surgeries during the incubation period of COVID-19 infection. EClinicalMedicine [Internet]. 2020;21:100331. https://doi.org/10. 1016/j.eclinm.2020.100331.

36. Li X, Xu S, Yu M, Wang K, Tao Y, Zhou Y, et al. Risk factors for severity and mortality in adult COVID-19 inpatients in Wuhan. J Allergy Clin Immunol. 2020;146(1):110-8. https://doi.org/10. 1016/j.jaci.2020.04.006.

37. Liu T, Zhang J, Yang Y, Ma H, Li Z, Zhang J, et al. The potential role of IL-6 in monitoring severe case of coronavirus disease 2019. medRxiv [Internet]. 2020; Available from: https://www.medrxiv. org/content/early/2020/03/10/2020.03.01.20029769. Accessed 13 June 2020.

38. Liu Y, Sun W, Li J, Chen L, Wang Y, Zhang L, et al. Clinical features and progression of acute respiratory distress syndrome in coronavirus disease 2019. medRxiv [Internet]. 2020; Available from: https://www.medrxiv.org/content/early/2020/02/27/2020.02. 17.20024166. Accessed 13 June 2020.

39. Sun L, Shen L, Fan J, Gu F, Hu M, An Y, et al. Clinical features of patients with coronavirus disease 2019 from a designated hospital in Beijing, China. J Med Virol. 2020. https://doi.org/10.1002/jmv. 25966.

40. Xu Y, Xu Z, Liu X, Cai L, Zheng H, Huang Y, et al. Clinical findings in critical ill patients infected with SARS-Cov-2 in Guangdong Province, China: a multi-center, retrospective, observational study [Internet]. medRxiv. 2020. Available from: https:// doi.org/10.1101/2020.03.03.20030668.

41. Yang L, Liu J, Zhang R, Li M, Li Z, Zhou X, et al. Epidemiological and clinical features of 200 hospitalized patients with corona virus disease 2019 outside Wuhan, China: a descriptive study. J Clin Virol. 2020;129:104475. https://doi.org/10.1016/j.jcv.2020. 104475.

42. Yang X, Yu Y, Xu J, Shu H, Liu H, Wu Y, et al. Clinical course and outcomes of critically ill patients with SARS-CoV-2 pneumonia in Wuhan, China: a single-centered, retrospective, observational study. Lancet Respir Med. 2020;8(5):475-81.

43. Zha L, Li S, Pan L, Tefsen B, Li Y, French N, et al. Corticosteroid treatment of patients with coronavirus disease 2019 (COVID-19). Med J Aust. 2020;212(9):416-20.

44. Zhao XY, Xu XX, Yin HS, Hu QM, Xiong T, Tang YY, et al. Clinical characteristics of patients with 2019 coronavirus disease in a non-Wuhan area of Hubei Province, China: a retrospective study. BMC Infect Dis. 2020;20(311):1-8.

45. Cao J, Hu X, Cheng W, Yu L, Tu W-J, Liu Q. Clinical features and short-term outcomes of 18 patients with corona virus disease 2019 in intensive care unit. Intensive Care Med. 2020;46:851-3. 
46. Chen X, Zheng F, Qing Y, Ding S, Yang D, Lei C, et al. Epidemiological and clinical features of 291 cases with coronavirus disease 2019 in areas adjacent to Hubei, China: a double-center observational study. medRxiv [Internet]. 2020; Available from: https://www.medrxiv.org/content/early/2020/03/06/2020.03.03. 20030353. Accessed 13 June 2020.

47. Lo IL, Lio CF, Cheong HH, Lei CI, Cheong TH, Zhong X, et al. Evaluation of SARS-CoV-2 RNA shedding in clinical specimens and clinical characteristics of 10 patients with COVID-19 in Macau. Int J Biol Sci [Internet]. 2020;16(10):1698-707 Available from: https://europepmc.org/articles/PMC7098032.

48. Wan S, Xiang Y, Fang W, Zheng Y, Li B, Hu Y, et al. Clinical features and treatment of COVID-19 patients in Northeast Chongqing. J Med Virol [Internet]. 2020;92(7):797-806. Available from: https://doi.org/10.1002/jmv.25783.

49. Wang D, Hu B, Hu C, Zhu F, Liu X, Zhang J, et al. Clinical characteristics of 138 hospitalized patients with 2019 novel coronavirus-infected pneumonia in Wuhan, China. JAMA [Internet]. 2020;323(11):1061-9 Available from: https://doi.org/ 10.1001/jama.2020.1585.

50. Xu Y, Li Y, Zeng Q, Lu Z, Li Y, Wu W, et al. Clinical characteristics of SARS-CoV-2 pneumonia compared to controls in Chinese Han population. medRxiv [Internet]. 2020; Available from: https:// www.medrxiv.org/content/early/2020/03/10/2020.03.08. 20031658. Accessed 13 June 2020.

51. Zhang GQ, Hu C, Luo LJ, Fang F, Chen YF, Li JG, et al. Clinical features and treatment of 221 patients with COVID-19 in Wuhan, China. 2020; Available from: Zhang, Gu-qin and $\mathrm{Hu}$, Chang and Luo, Lin-jie and Fang, Fang and Chen, Yong-feng and Li, Jian-guo and Peng, Zhi-yong and Pan, Huaqin, Clinical Features and Treatment of 221 Patients with COVID-19 in Wuhan, China $(2 / 27 / 2020)$. Available at SSRN: https://ssrn.com/abstract=3546095 or. https://doi.org/10.2139/ssrn.3546095.

52. Estimating the sample mean and standard deviation from the sample size, median, range and/or interquartile range [Internet]. Alexa Crawls. [cited 2020 Jun 12]. Available from: https://web.archive. org/web/20181224162602/http://www.comp.hkbu.edu.hk/ xwan/ median2mean.html. Accessed 13 June 2020.

53. ClinicalTrials.gov [Internet]. NIH U.S. National Library of Medicine. 2020 [cited 2020 Jun 11]. Available from: https:// clinicaltrials.gov/ct $2 /$ results?term $=$ Corticosteroids\&cond $=$
COVID $+19 \&$ Search $=$ Apply \&age_v $=\&$ gndr $=\&$ type $=\&$ rslt $=$. Accessed 13 June 2020

54. Wong CK, Lam CWK, Wu AKL, Ip WK, Lee NLS, Chan IHS, et al. Plasma inflammatory cytokines and chemokines in severe acute respiratory syndrome. Clin Exp Immunol. 2004;136(1):95103.

55. Mahallawi WH, Khabour OF, Zhang Q, Makhdoum HM, Suliman BA. MERS-CoV infection in humans is associated with a proinflammatory Th1 and Th17 cytokine profile. Cytokine. 2018;104:8-13.

56. Veronese N, Demurtas J, Yang L, Tonelli R, Barbagallo M, Lopalco P, et al. Use of corticosteroids in coronavirus disease 2019 pneumonia: a systematic review of the literature. Front Med. 2020;7:170. https://doi.org/10.3389/fmed.2020.00170.

57. Lu S, Zhou Q, Huang L, Shi Q, Zhao S, Wang Z, et al. Effectiveness and safety of glucocorticoids to treat COVID-19: a rapid review and meta-analysis. medRxiv. 2020;2020.04.17.20064469.

58. Li H, Chen C, Hu F, Wang J, Zhao Q, Gale RP, et al. Impact of corticosteroid therapy on outcomes of persons with SARS-CoV-2, SARS-CoV, or MERS-CoV infection: a systematic review and meta-analysis. Leukemia. 2020;34(6):1503-11.

59. Search of: dexamethasone | covid-19 - List Results - ClinicalTrials. gov. https://clinicaltrials.gov/ct2/results?cond=covid-19\&term= dexamethasone $\&$ cntry $=\&$ state $=\&$ city $=\&$ dist $=$. Accessed August 29, 2020.

60. Pennica A, Conforti G, Falangone F, Martocchia A, Tafaro L, Sentimentale A, et al. Clinical management of adult coronavirus infection disease 2019 (COVID-19) positive in the setting of low and medium intensity of care: a short practical review. SN Compr Clin Med. 2020;2(6):694-9. https://doi.org/10.1007/s42399-02000333-w.

61. WHO welcomes preliminary results about dexamethasone use in treating critically ill COVID-19 patients. https://www.who.int/ news-room/detail/16-06-2020-who-welcomes-preliminary-resultsabout-dexamethasone-use-in-treating-critically-ill-covid-19patients. Accessed August 29, 2020.

Publisher's Note Springer Nature remains neutral with regard to jurisdictional claims in published maps and institutional affiliations. 